\title{
17ß-Hydroxysteroid Dehydrogenase Type 1 Inhibition: A Potential Treatment Option for Non-Small Cell Lung Cancer
}

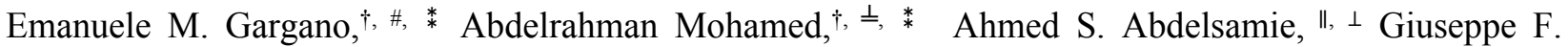
Mangiatordi, $₫$ Hanna Drzewiecka, ${ }^{\S}$ Paweł P. Jagodziński, ${ }^{\S}$ Arcangela Mazzini, ${ }^{\dagger}$ Chris J. van Koppen, Matthias W. Laschke, ${ }^{\ddagger}$ Orazio Nicolotti, ${ }^{\ddagger}$ Angelo Carotti,, Sandrine Marchais-Oberwinkler ${ }^{\dagger}{ }^{\star}$ Rolf W. Hartmann, ${ }^{\dagger,}, \|$ and Martin Frotscher ${ }^{+*}$

†Department of Pharmacy, Pharmaceutical and Medicinal Chemistry, Saarland University, Campus C2.3, D-66123 Saarbrücken, Germany.

${ }^{\perp}$ Pharmaceutical Organic Chemistry Department, Assiut University, Assiut, Egypt.

"Department of Drug Design and Optimization, Helmholtz Institute for Pharmaceutical Research Saarland (HIPS), Campus E8.1, D-66123 Saarbrücken, Germany.

${ }^{\perp}$ Chemistry of Natural and Microbial Products Department, National Research Centre, Dokki, 12311 Cairo, Egypt.

†Dipartimento di Farmacia Scienze del Farmaco, Università degli Studi di Bari, V. Orabona 4, I-70125 Bari, Italy.

§Department of Biochemistry and Molecular Biology, Poznan University of Medical Sciences, Święcickiego 6 Street, 60-781 Poznan, Poland.

"ElexoPharm GmbH, Campus A12, D-66123 Saarbrücken, Germany.

${ }^{\sharp}$ Institute for Clinical and Experimental Surgery, Saarland University, D-66421, Homburg/Saar, Germany.

* These authors contributed equally to this work (Co-first authorship).

\section{Supporting Information}

\section{Table of contents}

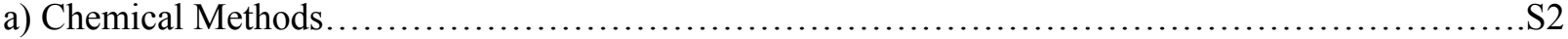

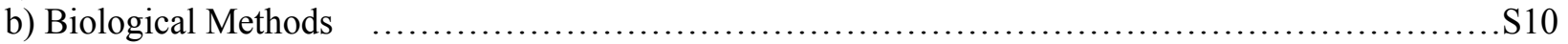

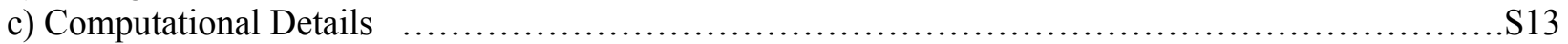

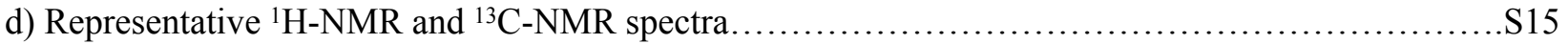

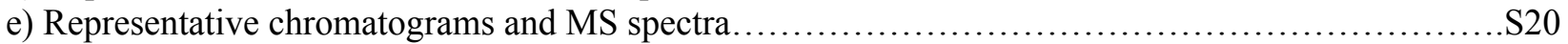

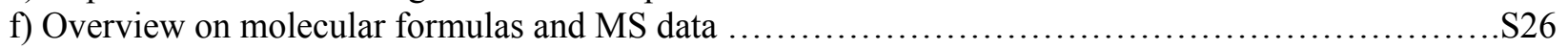

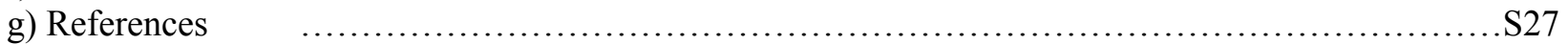

a) Chemical Methods. Chemical names follow IUPAC nomenclature. Starting materials were purchased from Aldrich, Acros, Combi-Blocks or Fluorochem and were used without purification.

Normal pressure column chromatography was performed on silica gel (70-200 $\mu \mathrm{m})$ and reaction progress was monitored by TLC on Alugram SIL G/UV254 (Macherey-Nagel). Visualization was accomplished with UV light. ${ }^{1} \mathrm{H}$ and ${ }^{13} \mathrm{C}-\mathrm{NMR}$ spectra were measured on a Bruker-500 (at $500 \mathrm{MHz}$ and $126 \mathrm{MHz}$, respectively) or Bruker-300 (at $300 \mathrm{MHz}$ and $75 \mathrm{MHz}$, respectively). Chemical shifts are reported in $\delta$ (parts per million: $\mathrm{ppm}$ ), using residual peaks of the deuterated solvents as internal standard: $\left(\mathrm{CD}_{3}\right)_{2} \mathrm{SO}$ (DMSO- $\left.d 6\right): 2.50 \mathrm{ppm}$ ( $\left.{ }^{1} \mathrm{H}-\mathrm{NMR}\right), 39.52 \mathrm{ppm}\left({ }^{13} \mathrm{C}-\mathrm{NMR}\right) ;\left(\mathrm{CD}_{3}\right)_{2} \mathrm{CO}$ (acetone-d6): $2.05 \mathrm{ppm}$ ( $\left.{ }^{1} \mathrm{H}-\mathrm{NMR}\right), 29.84 \mathrm{ppm}$ and 206.26 ppm ( $\left.{ }^{13} \mathrm{C}-\mathrm{NMR}\right) ; \mathrm{CDCl}_{3}$ (Chloroform- $d$ ): 2.05 ppm ( $\left.{ }^{1} \mathrm{H}-\mathrm{NMR}\right), 29.84 \mathrm{ppm}$ and $206.26 \mathrm{ppm}$ ( $\left.{ }^{13} \mathrm{C}-\mathrm{NMR}\right)$. 
Signals are described as br (broad), s (singlet), d (doublet), t (triplet), dd (doublet of doublets), ddd (doublet of doublet of doublets), dt (doublet of triplets) and m (multiplet). All coupling constants $(J)$ are given in Hertz (Hz). Melting points (mp) were measured in open capillaries on a Stuart Scientific SMP3 apparatus and are uncorrected.

Mass spectrometry was performed on a TSQ Quantum (ThermoFisher, Dreieich, Germany). The triple quadrupole mass spectrometer was equipped with an electrospray interface (ESI). The purity of the compounds was assessed by LC/MS. The Surveyor-LC-system consisted of a pump, an auto sampler, and a PDA detector. The system was operated by the standard software Xcalibur. A RP C18 NUCLEODUR 100-5 ( $3 \mathrm{~mm}$ ) column (Macherey-Nagel $\mathrm{GmbH}$, Dühren, Germany) was used as stationary phase. All solvents were HPLC grade. In a gradient run the percentage of acetonitrile (containing $0.1 \%$ trifluoroacetic acid) was increased from an initial concentration of $20 \%$ at $0 \min$ to $100 \%$ at $12 \mathrm{~min}$ and kept at $100 \%$ for 3 min. The injection volume was $20 \mu \mathrm{L}$ and flow rate was set to $700 \mu \mathrm{L} / \mathrm{min}$.

MS analysis was carried out at a needle voltage of $3000 \mathrm{~V}$ and a capillary temperature of $350{ }^{\circ} \mathrm{C}$. Mass spectra were acquired in positive mode, using an electron spray ionization method, from 100 to $1000 \mathrm{~m} / \mathrm{z}$ and UV spectra were recorded at the wave length of $254 \mathrm{~nm}$ and in some cases at $360 \mathrm{~nm}$. IR spectra were recorded for selected compounds on a Bruker Vector 33 spectrometer (neat sample).

All microwave irradiation experiments were carried out in a 507 CEM-Discover microwave apparatus.

All tested compounds exhibited $\geq 95 \%$ chemical purity as measured by LC/MS.

\section{Method A, general procedure for amide formation:}

A mixture of 5-bromofuran-2-carboxylic acid (1eq), thionyl chloride (2.5 eq) and DMF (5 drops) in toluene $(10 \mathrm{~mL})$ was refluxed at $110^{\circ} \mathrm{C}$ for 4 hours. The reaction mixture was cooled to room temperature; the solvent and the excess of thionyl chloride were removed under reduced pressure. The corresponding $\mathrm{N}$ methylamine ( $1 \mathrm{eq})$ and $\mathrm{Et}_{3} \mathrm{~N}(1 \mathrm{eq})$ in $\mathrm{CH}_{2} \mathrm{Cl}_{2}(10 \mathrm{~mL})$ was added at $0^{\circ} \mathrm{C}$ under $\mathrm{N}_{2}$ atmosphere to the acyl chloride. After 30 minutes at $0^{\circ} \mathrm{C}$, the ice bath was removed and the solution was warmed up and stirred at room temperature overnight. The reaction mixture was extracted twice with $\mathrm{CH}_{2} \mathrm{Cl}_{2}(2 \times 15 \mathrm{~mL})$; the organic layer was dried over $\mathrm{MgSO}_{4}$, filtered and the solution was concentrated under reduced pressure. The residue was purified by silica gel column chromatography using hexanes and EtOAc as eluent or by trituration in a mixture of diethyl ether / petroleum ether to afford the desired compound.

\section{Method B, general procedure for Suzuki-Miyaura coupling:}

In a sealed tube the previously prepared 5-bromo- $N$-heteroaryl-furan-2-carboxamide derivative ( 1 eq.) was introduced followed by the corresponding boronic acid (1.5 eq.), cesium carbonate (3 eq.), tetrakis (triphenylphosphine)palladium (0.02 eq.) and a mixture of DME/EtOH/ $\mathrm{H}_{2} \mathrm{O}(1: 1: 1, \mathrm{v}: \mathrm{v}: \mathrm{v}, 3 \mathrm{~mL})$ as solvent. The reactor was flushed with $\mathrm{N}_{2}$ and submitted to microwave irradiation $\left(150{ }^{\circ} \mathrm{C}, 150 \mathrm{~W}\right)$ for 20 minutes. After cooling to room temperature, a mixture of EtOAc/ $\mathrm{H}_{2} \mathrm{O}(1: 1, \mathrm{v}: \mathrm{v}, 2 \mathrm{~mL})$ was added to stop the reaction. The aqueous layer was extracted with EtOAc $(3 \times 10 \mathrm{~mL})$. The organic layer was washed once with brine and once with water, dried over $\mathrm{MgSO}_{4}$, filtered and the solution was concentrated under reduced pressure. The residue was purified by column chromatography using hexanes and EtOAc as eluent to afford the desired compound. 


\section{Method C, general procedure for ether cleavage:}

To a solution of methoxyaryl compounds ( 1 eq) in dry dichloromethane $(5 \mathrm{~mL} / \mathrm{mmol}$ of reactant), boron trifluoride-dimethyl sulfide complex (6 eq./methoxy function) was added dropwise at $0{ }^{\circ} \mathrm{C}$ and stirred for 6-14 $\mathrm{h}$ at room temperature. After the reaction was finished, the reaction mixture was diluted with dichloromethane and $5 \%$ aqueous $\mathrm{NaHCO}_{3}$ was added until neutral $\mathrm{pH}$ was obtained. The aqueous layer wad extracted with dichloromethane. The combined organic layers were washes with brine, dried over sodium sulfate, evaporated to dryness under reduced pressure. The product was purified by column chromatography using EtOAc as eluent to afford the desired compound.

5-Bromo- $N$-methyl- $N$-(o-tolyl)furan-2-carboxamide 1b<smiles>Cc1ccccc1N(C)C(=O)c1ccc(Br)o1</smiles>

The title compound was prepared by reaction of 5-bromofuran-2-carboxylic acid (500 mg, $2.6 \mathrm{mmol})$, thionyl chloride $(0.5 \mathrm{~mL}, 6.8 \mathrm{mmol})$ and $N$,2-dimethylaniline $(315 \mathrm{mg}, 2.6 \mathrm{mmol})$ according to method A. The residue was purified by silica gel column chromatography ( $n$-hexane/ethyl acetate 70:30) to afford the desired product as grey solid (349 mg, $45 \%$ ). $\mathrm{C}_{13} \mathrm{H}_{12} \mathrm{BrNO}_{2}$; MW 294; mp: 93 - 95 ${ }^{\circ} \mathrm{C}$; MS (ESI) 294, 296 $[\mathrm{M}+\mathrm{H}]^{+} ;{ }^{1} \mathrm{H}-\mathrm{NMR}\left(500 \mathrm{MHz}, \mathrm{DMSO}-d_{6}\right) \delta 7.39-7.32(\mathrm{~m}, 2 \mathrm{H}), 7.34-7.24(\mathrm{~m}, 2 \mathrm{H}), 6.47(\mathrm{~d}, J=3.6 \mathrm{~Hz}$, $1 \mathrm{H}), 5.51(\mathrm{~d}, J=3.6 \mathrm{~Hz}, 1 \mathrm{H}), 3.21(\mathrm{~s}, 3 \mathrm{H}), 2.12(\mathrm{~s}, 3 \mathrm{H}) ;{ }^{13} \mathrm{C}-\mathrm{NMR}\left(126 \mathrm{MHz}\right.$, acetone- $\left.d_{6}\right) \delta 158.3,150.6$, $142.5,138.7,131.1,129.5,129.2,128.2,125.1,118.9,113.9,38.4,21.2$.

5-(4-Methoxy-3,5-dimethylphenyl)- $N$-methyl- $N$-(o-tolyl)furan-2-carboxamide 1a<smiles>COc1c(C)cc(-c2ccc(C(=O)N(C)c3ccccc3C)o2)cc1C</smiles>

The title compound was prepared by reaction of $\mathbf{1 b}(500 \mathrm{mg}, 1.70 \mathrm{mmol})$, (4-methoxy-3,5 dimethylphenyl) boronic acid (367 mg, $2.04 \mathrm{mmol})$, cesium carbonate $(1662 \mathrm{mg}, 5.10 \mathrm{mmol}$ ) and tetrakis(triphenylphoshine) palladium (39 mg, 0.02 eq.) according to method B. The residue was purified by silica gel column chromatography ( $n$-hexane/ethyl acetate 70:30) to afford the desired product as yellow solid (75 $\mathrm{mg}, 65 \%$ ). $\mathrm{C}_{22} \mathrm{H}_{23} \mathrm{NO}_{3}$; MW 349; mp: $128-132{ }^{\circ} \mathrm{C}$ MS (ESI) $350[\mathrm{M}+\mathrm{H}]^{+} ;{ }^{1} \mathrm{H}-\mathrm{NMR}\left(500 \mathrm{MHz}\right.$, acetone- $\left.d_{6}\right) \delta$ 7.33-7.43 (m, 3H), 7.29 (dd, $J=2,8 \mathrm{~Hz}, 1 \mathrm{H}), 6.94$ (brs, 2H), $6.64(\mathrm{~d}, J=3 \mathrm{~Hz}, 1 \mathrm{H}), 6.62(\mathrm{~d}, J=3 \mathrm{~Hz}, 1 \mathrm{H}), 3.68$ (s, $3 \mathrm{H}), 3.30(\mathrm{~s}, 3 \mathrm{H}), 2.22(\mathrm{~s}, 9 \mathrm{H}) ;{ }^{13} \mathrm{C}-\mathrm{NMR}\left(126 \mathrm{MHz}\right.$, acetone- $\left.d_{6}\right) \delta 159.1,158.4,156.0,148.1,144.6,136.8$, 132.2, 132.1, 129.2, 129.1, 128.3, 126.3, 125.6, 119.3, 106.4, 60.6, 37.5, 17.6, 16.1; IR (cm-1) 3049, 2981, 2924, 2856, 1626.

5-(4-Methoxy-3-methylphenyl)- $N$-methyl- $N$-(o-tolyl)furan-2-carboxamide 2a 


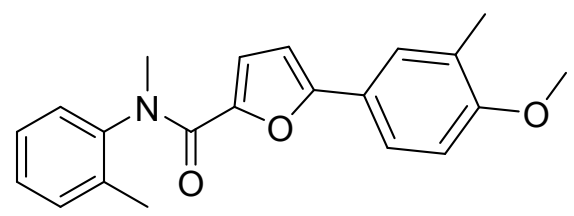

The title compound was prepared by reaction of $\mathbf{1 b}(500 \mathrm{mg}, 1.70 \mathrm{mmol})$, (4-methoxy-3-methylphenyl) boronic acid (339 mg, $2.04 \mathrm{mmol})$, cesium carbonate $(1662 \mathrm{mg}, 5.10 \mathrm{mmol}$ ) and tetrakis(triphenylphoshine) palladium (39 mg, 0.02 eq.) according to method B. The residue was purified by silica gel column chromatography ( $n$-hexane/ethyl acetate 90:10) to afford the desired product as colorless oil (213 mg, 37\%). $\mathrm{C}_{21} \mathrm{H}_{21} \mathrm{NO}_{3}$; MW 335; MS (ESI) $336[\mathrm{M}+\mathrm{H}]^{+}$; ${ }^{1} \mathrm{H}-\mathrm{NMR}\left(500 \mathrm{MHz}\right.$, acetone- $\left.d_{6}\right) \delta 7.44-7.26(\mathrm{~m}, 4 \mathrm{H}), 7.19$ $(\mathrm{dd}, J=8.6,2.3 \mathrm{~Hz}, 1 \mathrm{H}), 7.04-7.00(\mathrm{~m}, 1 \mathrm{H}), 6.87(\mathrm{~d}, J=8.5 \mathrm{~Hz}, 1 \mathrm{H}), 6.58(\mathrm{~d}, J=3.6 \mathrm{~Hz}, 1 \mathrm{H}), 6.51(\mathrm{~d}, J$ $=3.6 \mathrm{~Hz}, 1 \mathrm{H}), 3.83(\mathrm{~s}, 3 \mathrm{H}), 3.29(\mathrm{~s}, 3 \mathrm{H}), 2.22(\mathrm{~s}, 3 \mathrm{H}), 2.15(\mathrm{~s}, 3 \mathrm{H}) ;{ }^{13} \mathrm{C}-\mathrm{NMR}\left(126 \mathrm{MHz}\right.$, acetone- $\left.d_{6}\right) \delta 159.2$, $159.1,156.4,147.6,144.5,136.8,132.2$, 129.2, 129.1, 128.3, 127.5, 127.3, 124.3, 123.1, 119.2, 111.1, 105.5, 55.9, 37.4, 17.6, 16.2; IR and $\left(\mathrm{cm}^{-1}\right)$ 3052, 2933, $2838,1627$.

5-(4-Methoxy-2-methylphenyl)- $N$-methyl- $N$-(o-tolyl)furan-2-carboxamide 3a<smiles>COc1ccc(-c2ccc(C(=O)N(C)c3ccccc3C)o2)c(C)c1</smiles>

The title compound was prepared by reaction of $\mathbf{1 b}(500 \mathrm{mg}, 1.70 \mathrm{mmol})$, (4-methoxy-2-methylphenyl) boronic acid (339 mg, $2.04 \mathrm{mmol}$ ), cesium carbonate (1662 mg, $5.10 \mathrm{mmol}$ ) and tetrakis(triphenylphoshine) palladium (39 mg, $0.02 \mathrm{eq}$ ) according to method B. The residue was purified by silica gel column chromatography ( $n$-hexane/ethyl acetate 90:10) to afford the desired product as white solid (247 $\mathrm{mg}, 41 \%)$. $\mathrm{C}_{21} \mathrm{H}_{21} \mathrm{NO}_{3}$; MW 335; mp : 90-93 ${ }^{\circ} \mathrm{C}$ MS (ESI) $336[\mathrm{M}+\mathrm{H}]^{+}$; ${ }^{1} \mathrm{H}-\mathrm{NMR}\left(500 \mathrm{MHz}\right.$, acetone- $\left.d_{6}\right) \delta$ 7.27-7.40 $(\mathrm{m}, 4 \mathrm{H}), 6.99(\mathrm{~d}, J=7 \mathrm{~Hz}, 1 \mathrm{H}), 6.78(\mathrm{~s}, 1 \mathrm{H}), 6.72(\mathrm{dd}, J=2 \mathrm{~Hz}, 8 \mathrm{~Hz}, 1 \mathrm{H}), 6.42(\mathrm{~d}, J=3 \mathrm{~Hz}, 1 \mathrm{H}), 6.33(\mathrm{~d}$, $J=3 \mathrm{~Hz}, 1 \mathrm{H}), 3.79(\mathrm{~s}, 3 \mathrm{H}), 3.29(\mathrm{~s}, 3 \mathrm{H}), 2.35(\mathrm{~s}, 3 \mathrm{H}), 2.22(\mathrm{~s}, 3 \mathrm{H}),{ }^{13} \mathrm{C}-\mathrm{NMR}\left(126 \mathrm{MHz}\right.$, acetone- $\left.d_{6}\right) \delta 160.6$, $159.3,155.6,147.2$, 144.4, 137.6, 136.7, 132.3, 129.6, 129.2, 129.1, 128.4, 122.8, 118.6, 117.2, 112.4, 109.4, 55.6, 37.4, 22.1, 17.6; IR $\left(\mathrm{cm}^{-1}\right)$ 3052, 2960, 2936, 2859, 2835, 1639.

5-(4-Methoxyphenyl)- $N$-methyl- $N$-(o-tolyl)furan-2-carboxamide 4a<smiles>COc1ccc(-c2ccc(C(=O)N(C)c3ccccc3C)o2)cc1</smiles>

The title compound was prepared by reaction of $\mathbf{1 b}(80 \mathrm{mg}, 0.27 \mathrm{mmol})$, (4-methoxyphenyl)boronic acid (54 mg, $0.35 \mathrm{mmol})$, cesium carbonate $(266 \mathrm{mg}, 0.82 \mathrm{mmol})$ and tetrakis(triphenylphoshine) palladium (6 $\mathrm{mg}, 0.02$ eq.) according to method B. The residue was purified by silica gel column chromatography ( $n$ hexane/ethyl acetate 70:30) to afford the desired product as yellow solid (52 mg, 29\%). $\mathrm{C}_{20} \mathrm{H}_{19} \mathrm{NO}_{3}$; MW 321; mp: 92-95 ${ }^{\circ} \mathrm{C}$; MS (ESI) $322[\mathrm{M}+\mathrm{H}]{ }^{+}$; ${ }^{1} \mathrm{H}-\mathrm{NMR}\left(500 \mathrm{MHz}, \mathrm{DMSO}-d_{6}\right) \delta 7.42-7.26(\mathrm{~m}, 4 \mathrm{H}), 7.23(\mathrm{~d}$, $J=8.7 \mathrm{~Hz}, 2 \mathrm{H}), 6.90(\mathrm{~d}, J=8.8 \mathrm{~Hz}, 2 \mathrm{H}), 6.71(\mathrm{~d}, J=3.6 \mathrm{~Hz}, 1 \mathrm{H}), 6.36(\mathrm{~d}, J=3.6 \mathrm{~Hz}, 1 \mathrm{H}), 3.77(\mathrm{~s}, 3 \mathrm{H})$, $3.24(\mathrm{~s}, 3 \mathrm{H}), 2.16(\mathrm{~s}, 3 \mathrm{H}) ;{ }^{13} \mathrm{C}-\mathrm{NMR}\left(126 \mathrm{MHz}\right.$, acetone- $\left.d_{6}\right) \delta 160.9,159.1,156.0,147.6,144.4,136.7,132.1$, $129.2,129.0,128.2,126.6,123.5,119.0,114.9,105.6,55.7,37.3,17.5$. 
5-(2-Chloro-4-methoxyphenyl)- $N$-methyl- $N$-(o-tolyl)furan-2-carboxamide 5a<smiles>COc1ccc(-c2ccc(C(=O)N(C)c3ccccc3C)o2)c(Cl)c1</smiles>

The title compound was prepared by reaction of $\mathbf{1 b}(500 \mathrm{mg}, 1.70 \mathrm{mmol})$, (2-chloro-4-methoxyphenyl) boronic acid (380 mg, $2.04 \mathrm{mmol}$ ), cesium carbonate (1662 mg, $5.10 \mathrm{mmol}$ ) and tetrakis(triphenylphoshine) palladium (39 mg, 0.02 eq.) according to method B. The residue was purified by silica gel column chromatography ( $n$-hexane/ethyl acetate 90:10) to afford the desired product as white solid (150 mg, 25\%). $\mathrm{C}_{21} \mathrm{H}_{18} \mathrm{ClNO}_{3}$; MW 356; mp: 92-94 ${ }^{\circ} \mathrm{C}$; MS (ESI) 356, $358[\mathrm{M}+\mathrm{H}]^{+} ;{ }^{1} \mathrm{H}-\mathrm{NMR}$ (500 MHz, acetone- $d_{6}$ ) $\delta 7.41$ $-7.28(\mathrm{~m}, 4 \mathrm{H}), 7.00(\mathrm{~d}, J=2.6 \mathrm{~Hz}, 1 \mathrm{H}), 6.95(\mathrm{~d}, J=8.9 \mathrm{~Hz}, 1 \mathrm{H}), 6.89(\mathrm{~d}, J=3.7 \mathrm{~Hz}, 1 \mathrm{H}), 6.86(\mathrm{dd}, J=$ 8.9, $2.6 \mathrm{~Hz}, 1 \mathrm{H}), 6.50(\mathrm{~d}, J=3.7 \mathrm{~Hz}, 1 \mathrm{H}), 3.84(\mathrm{~s}, 3 \mathrm{H}), 3.30(\mathrm{~s}, 3 \mathrm{H}), 2.21(\mathrm{~s}, 3 \mathrm{H}) ;{ }^{13} \mathrm{C}-\mathrm{NMR}(126 \mathrm{MHz}$, acetone- $\left.d_{6}\right) \delta 161.0,159.0,152.1,147.7,144.4,136.8,132.3,131.8,130.2,129.22,129.16,128.4,121.7$, 118.7, 116.4, 114.4, 111.2, 56.2, 37.5, 17.6; IR $\left(\mathrm{cm}^{-1}\right)$ 2996, 2944, 2915, 2844, 1619.

5-(2-Fluoro-4-methoxyphenyl)- $N$-methyl- $N$-(o-tolyl)furan-2-carboxamide 6a<smiles>COc1ccc(-c2ccc(C(=O)N(C)c3ccccc3C)o2)c(F)c1</smiles>

The title compound was prepared by reaction of $\mathbf{1 b}(80 \mathrm{mg}, 0.27 \mathrm{mmol})$, (2-fluoro-4methoxyphenyl)boronic acid $(60 \mathrm{mg}, 0.35 \mathrm{mmol})$, cesium carbonate $(266 \mathrm{mg}, 0.82 \mathrm{mmol})$ and tetrakis(triphenylphoshine) palladium ( $6 \mathrm{mg}, 0.02$ eq.) according to method B. The residue was purified by silica gel column chromatography ( $n$-hexane/ethyl acetate 80:20) to afford the desired product as yellow oil (60 mg, 67\%). $\mathrm{C}_{20} \mathrm{H}_{18} \mathrm{FNO}_{3}$; MW 339; MS (ESI) $340[\mathrm{M}+\mathrm{H}]^{+} ;{ }^{1} \mathrm{H}-\mathrm{NMR}$ (500 MHz, acetone- $\left.d_{6}\right) \delta 7.41-$ $7.28(\mathrm{~m}, 4 \mathrm{H}), 6.97$ (t, $J=8.8 \mathrm{~Hz}, 1 \mathrm{H}), 6.81-6.72(\mathrm{~m}, 2 \mathrm{H}), 6.55$ (t, $J=3.7 \mathrm{~Hz}, 1 \mathrm{H}), 6.49$ (d, $J=3.6 \mathrm{~Hz}$, $1 \mathrm{H}), 3.84(\mathrm{~s}, 3 \mathrm{H}), 3.30(\mathrm{~s}, 3 \mathrm{H}), 2.22(\mathrm{~s}, 3 \mathrm{H}) ;{ }^{13} \mathrm{C}-\mathrm{NMR}\left(126 \mathrm{MHz}\right.$, acetone- $\left.d_{6}\right) \delta 162.2,162.1,161.7,159.7$, $159.0,150.2$, 147.6, 145.3, 144.4, 136.8, 132.2, 129.2, 129.1, 128.4, 128.1, 128.0, 119.1, 111.54, 111.52, $111.48,111.40,110.0,109.9,102.8,102.6,56.3,37.4,17.6$.

5-(3-Fluoro-4-methoxyphenyl)- $N$-methyl- $N$-(o-tolyl)furan-2-carboxamide 7a<smiles>COc1ccc(-c2ccc(C(=O)N(C)c3ccccc3C)o2)cc1F</smiles>

The title compound was prepared by reaction of $\mathbf{1 b}$ (100 $\mathrm{mg}, 0.34 \mathrm{mmol})$, (3-fluoro-4-methoxyphenyl) boronic acid (75 mg, $0.44 \mathrm{mmol})$, cesium carbonate $(332 \mathrm{mg}, 1.02 \mathrm{mmol}$ ) and tetrakis(triphenylphoshine) palladium ( $8 \mathrm{mg}, 0.02$ eq.) according to method B. The residue was purified by silica gel column chromatography ( $n$-hexane/ethyl acetate 70:30), to afford the desired product as a yellow oil (75 $\mathrm{mg}, 65 \%$ ). 
$\mathrm{C}_{20} \mathrm{H}_{18} \mathrm{FNO}_{3}$; MW 339; MS (ESI) $340[\mathrm{M}+\mathrm{H}]^{+} ;{ }^{1} \mathrm{H}-\mathrm{NMR}$ (500 MHz, Chloroform- $d$ ) $\delta 7.28-7.20$ (m, 2H), $7.18(\mathrm{dt}, J=7.5,4.4 \mathrm{~Hz}, 1 \mathrm{H}), 7.12-7.07(\mathrm{~m}, 1 \mathrm{H}), 6.93(\mathrm{ddd}, J=8.5,2.1,1.3 \mathrm{~Hz}, 1 \mathrm{H}), 6.82-6.71(\mathrm{~m}, 2 \mathrm{H})$, $6.35(\mathrm{~d}, J=3.6 \mathrm{~Hz}, 1 \mathrm{H}), 6.26(\mathrm{~d}, J=3.6 \mathrm{~Hz}, 1 \mathrm{H}), 3.77(\mathrm{~s}, 3 \mathrm{H}), 3.26(\mathrm{~s}, 3 \mathrm{H}), 2.13(\mathrm{~s}, 3 \mathrm{H}) ;{ }^{13} \mathrm{C}-\mathrm{NMR}(126$ $\mathrm{MHz}$, acetone- $\left.d_{6}\right) \delta 158.9,154.7,154.1,152.1,148.8,148.7,148.1,144.3,136.7,132.1,129.12,128.3$, $123.9,123.8,121.49,121.46,119.1,114.71,114.70,112.7,112.5,106.7,56.6,37.4,17.5$.

5-(3,5-Difluoro-4-methoxyphenyl)- $N$-methyl- $N$-(o-tolyl)furan-2-carboxamide 9a<smiles>COc1c(F)cc(-c2ccc(C(=O)N(C)c3ccccc3C)o2)cc1F</smiles>

The title compound was prepared by reaction of $\mathbf{1 b}(500 \mathrm{mg}, 1.70 \mathrm{mmol})$, (3,5-difluoro-4-methoxyphenyl) boronic acid (383 mg, $2.04 \mathrm{mmol})$, cesium carbonate $(1662 \mathrm{mg}, 5.10 \mathrm{mmol})$ and tetrakis(triphenylphoshine) palladium (39 mg, 0.02 eq.) according to method B. The residue was purified by silica gel column chromatography ( $n$-hexane/ethyl acetate 70:30) to afford the desired product as yellow oil (236 $\mathrm{mg}, 39 \%)$. $\mathrm{C}_{20} \mathrm{H}_{17} \mathrm{~F}_{2} \mathrm{NO}_{3}$; MW 357; mp : 70-72 ${ }^{\circ} \mathrm{C}$; MS (ESI) $358[\mathrm{M}+\mathrm{H}]^{+} ;{ }^{1} \mathrm{H}-\mathrm{NMR}\left(500 \mathrm{MHz}\right.$, acetone- $\left.d_{6}\right) \delta 7.30-$ $7.43(\mathrm{~m}, 4 \mathrm{H}), 6.89$ (d, $J=9 \mathrm{~Hz}, 2 \mathrm{H}), 6.84(\mathrm{~d}, J=4 \mathrm{~Hz}, 1 \mathrm{H}), 6.64(\mathrm{~d}, J=4 \mathrm{~Hz}, 1 \mathrm{H}), 3.97$ (s, 3H), 3.31 (s, 3H), 2.23 (s, 3H); ${ }^{13} \mathrm{C}-\mathrm{NMR}\left(126 \mathrm{MHz}\right.$, acetone- $\left.d_{6}\right) \delta 158.8,157.81,157.7,155.85,155.80,153.2,148.9$, 144.3, 137.2, 136.8, 132.2, 129.3, 129.2, 128.4, 126.1, 126.0, 125.9, 119.3, 109.1, 108.9, 108.8, 108.6, 62.4, 37.5, 17.6; IR $\left(\mathrm{cm}^{-1}\right) 2921,2847,1625$.

5-(3,5-Dichloro-4-methoxyphenyl)- $N$-methyl- $N$-(o-tolyl)furan-2-carboxamide 10a<smiles>COc1c(Cl)cc(-c2ccc(C(=O)N(C)c3ccccc3C)o2)cc1Cl</smiles>

The title compound was prepared by reaction of $\mathbf{1 b}(500 \mathrm{mg}, 1.70 \mathrm{mmol})$, (3,5-dichloro-4-methoxyphenyl) boronic acid (450 mg, $2.04 \mathrm{mmol})$, cesium carbonate $(1662 \mathrm{mg}, 5.10 \mathrm{mmol}$ ) and tetrakis(triphenylphoshine) palladium (39 mg, 0.02 eq.) according to method B. The residue was purified by silica gel column chromatography ( $n$-hexane/ethyl acetate 80:20) to afford the desired product as yellow solid (438 $\mathrm{mg}, 39 \%$ ). $\mathrm{C}_{20} \mathrm{H}_{17} \mathrm{Cl}_{2} \mathrm{NO}_{3}$; MW 390; mp : 114-117 ${ }^{\circ} \mathrm{C}$ MS (ESI) 390, $392[\mathrm{M}+\mathrm{H}]^{+} ;{ }^{1} \mathrm{H}-\mathrm{NMR}$ (300 MHz, acetone- $d_{6}$ ) $\delta$ 7.31-7.46 (m, 4H), 7.24 (s, 2H), 6.94 (d, $J=4 \mathrm{~Hz}, 1 \mathrm{H}), 6.78$ (d, $J=4 \mathrm{~Hz}, 1 \mathrm{H}), 3.89$ (s, 3H), 3.33 (s, 3H), $2.25(\mathrm{~s}, 3 \mathrm{H}) ;{ }^{13} \mathrm{C}-\mathrm{NMR}\left(75 \mathrm{MHz}\right.$, acetone- $\left.d_{6}\right) \delta 158.7,152.8,152.5,149.3,144.3,136.7,132.2,130.5,129.5$, $129.1,128.4,128.3,125.2,119.4,109.0,61.3,37.5,17.6$.

5-(4-Hydroxy-3,5-dimethylphenyl)- $N$-methyl- $N$-(o-tolyl)furan-2-carboxamide 1<smiles>Cc1ccccc1N(C)C(=O)c1ccc(-c2cc(C)c(O)c(C)c2)o1</smiles> 
The title compound was prepared by reaction of $1 \mathrm{a}(260 \mathrm{mg}, 0.74 \mathrm{mmol})$ and $\mathrm{BF}_{3} \cdot \mathrm{SMe}_{2}(470 \mu \mathrm{L}, 4.44$ mmol) according to method $\mathrm{C}$. The residue was purified by silica gel column chromatography ( $n$ hexane/ethyl acetate 60:40) to afford the desired product as yellow solid (74 mg, 30\%). $\mathrm{C}_{21} \mathrm{H}_{21} \mathrm{NO}_{3}$; $\mathrm{MW}$ 335; mp: 175-178 ${ }^{\circ} \mathrm{C}$; MS (ESI) $\left.336[\mathrm{M}+\mathrm{H}]\right]^{+}$; ${ }^{1} \mathrm{H}-\mathrm{NMR}(300 \mathrm{MHz}$, Chloroform- $d$ ) $\delta 7.21$ (dt, $J=16.6,4.3$ $\mathrm{Hz}, 3 \mathrm{H}), 7.10(\mathrm{~d}, J=7.3 \mathrm{~Hz}, 1 \mathrm{H}), 6.78(\mathrm{~s}, 2 \mathrm{H}), 6.37$ (d, $J=3.6 \mathrm{~Hz}, 1 \mathrm{H}), 6.21(\mathrm{~d}, J=3.5 \mathrm{~Hz}, 1 \mathrm{H}), 6.03(\mathrm{~s}$, 1H), 3.27 (s, 3H), $2.15-2.08(\mathrm{~m}, 9 \mathrm{H}) ;{ }^{13} \mathrm{C}-\mathrm{NMR}$ (75 MHz, Chloroform-d) $\delta$ 159.6, 156.5, 153.4, 145.4, 143.1, 135.8, 131.4, 128.4, 128.1, 127.4, 124.8, 123.9, 121.6, 119.5, 104.4, 37.6, 17.4, 16.0; IR (cm-1) 3274, 2952, 2912, 1614, 1592.

5-(4-Hydroxy-3-methylphenyl)- $N$-methyl- $N$-(o-tolyl)furan-2-carboxamide 2

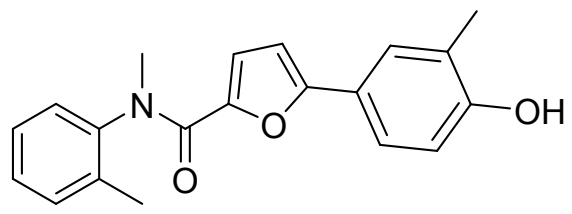

The title compound was prepared by reaction of $2 \mathbf{a}(224 \mathrm{mg}, 0.67 \mathrm{mmol})$ and $\mathrm{BF}_{3} \cdot \mathrm{SMe}_{2}(420 \mu \mathrm{L}, 4.02$ $\mathrm{mmol}$ ) according to method $\mathrm{C}$. The residue was purified by crystallization in water and ethanol to afford the desired product as green solid (140 mg, 65\%). $\mathrm{C}_{20} \mathrm{H}_{19} \mathrm{NO}_{3}$; MW 321; mp: 183-186 ${ }^{\circ} \mathrm{C}$; MS (ESI) 322 $[\mathrm{M}+\mathrm{H}]^{+} ;{ }^{1} \mathrm{H}-\mathrm{NMR}\left(500 \mathrm{MHz}, \mathrm{DMSO}-d_{6}\right) \delta 9.66(\mathrm{~s}, 1 \mathrm{H}), 7.42-7.25(\mathrm{~m}, 4 \mathrm{H}), 7.02(\mathrm{~d}, 1 \mathrm{H}), 6.87(\mathrm{~s}, 1 \mathrm{H})$, $6.71(\mathrm{~d}, J=8.3 \mathrm{~Hz}, 1 \mathrm{H}), 6.60(\mathrm{~d}, J=3.7 \mathrm{~Hz}, 1 \mathrm{H}), 6.42(\mathrm{~d}, J=3.7 \mathrm{~Hz}, 1 \mathrm{H}), 3.23(\mathrm{~s}, 3 \mathrm{H}), 2.14(\mathrm{~s}, 3 \mathrm{H}), 2.08$ $(\mathrm{s}, 3 \mathrm{H}) ;{ }^{13} \mathrm{C}-\mathrm{NMR}\left(126 \mathrm{MHz}, \mathrm{DMSO}-d_{6}\right) \delta 157.9,156.0,155.3,145.4,142.9,135.2,131.1,128.18,128.11$, $127.3,126.3,124.3,123.0,120.2,118.5,114.7,104.4,36.9,17.0,15.7$; IR $\left(\mathrm{cm}^{-1}\right) 3132,2907,1573$.

5-(4-Hydroxy-2-methylphenyl)- $N$-methyl- $N$-(o-tolyl)furan-2-carboxamide 3<smiles>Cc1cc(O)ccc1-c1ccc(C(=O)N(C)c2ccccc2C)o1</smiles>

The title compound was prepared by reaction of $3 \mathbf{a}(200 \mathrm{mg}, 0.60 \mathrm{mmol})$ and $\mathrm{BF}_{3} \cdot \mathrm{SMe}_{2}(468 \mu \mathrm{L}, 3.60$ mmol) according to method $\mathrm{C}$. The residue was purified by silica gel column chromatography ( $n$ hexane/ethyl acetate 60:40) to afford the desired product as white solid (178 mg, 92\%). $\mathrm{C}_{20} \mathrm{H}_{19} \mathrm{NO}_{3}$; MW 321; mp: 219-221 ${ }^{\circ} \mathrm{C}$; MS (ESI) $322[\mathrm{M}+\mathrm{H}]^{+}$; ${ }^{1} \mathrm{H}-\mathrm{NMR}\left(500 \mathrm{MHz}, \mathrm{DMSO}-d_{6}\right) \delta 9.64(\mathrm{~s}, 1 \mathrm{H}), 7.26-7.38(\mathrm{~m}$, $4 \mathrm{H}), 6.83(\mathrm{~d}, J=8 \mathrm{~Hz}, 1 \mathrm{H}), 6.62(\mathrm{~s}, 1 \mathrm{H}), 6.55(\mathrm{~d}, J=7 \mathrm{~Hz}, 1 \mathrm{H}), 6.42(\mathrm{~d}, J=3 \mathrm{~Hz}, 1 \mathrm{H}), 6.20(\mathrm{~d}, J=3 \mathrm{~Hz}$, $1 \mathrm{H}), 3.23(\mathrm{~s}, 3 \mathrm{H}), 2.23(\mathrm{~s}, 3 \mathrm{H}), 2.15(\mathrm{~s}, 3 \mathrm{H}) ;{ }^{13} \mathrm{C}-\mathrm{NMR}\left(126 \mathrm{MHz}, \mathrm{DMSO}-d_{6}\right) \delta$ 158.0, 157.5, 154.6, 145.1, 142.8, 136.3, 135.2, 131.2, 128.4, 128.2, 128.1, 127.4, 119.8, 117.8, 117.6, 113.0, 108.1, 36.9, 21.3, 17.0; IR $\left(\mathrm{cm}^{-1}\right) 3243,3056,2966,2920,2853,1616$.

5-(4-Hydroxyphenyl)- $N$-methyl- $N$-(o-tolyl)furan-2-carboxamide 4<smiles>Cc1ccccc1N(C)C(=O)c1ccc(-c2ccc(O)cc2)o1</smiles> 
The title compound was prepared by reaction of $4 \mathbf{a}(50 \mathrm{mg}, 0.16 \mathrm{mmol})$ and $\mathrm{BF}_{3} \cdot \mathrm{SMe}_{2}(100 \mu \mathrm{L}, 0.96 \mathrm{mmol})$ according to method $\mathrm{C}$. The residue was purified silica gel column chromatography ( $n$-hexane/ethyl acetate 60:40) to afford the desired product as yellow solid (45 mg, 92\%). $\mathrm{C}_{19} \mathrm{H}_{17} \mathrm{NO}_{3}$; MW 307; mp: 172-175 ${ }^{\circ} \mathrm{C}$; MS (ESI) $308[\mathrm{M}+\mathrm{H}]^{+} ;{ }^{1} \mathrm{H}-\mathrm{NMR}\left(500 \mathrm{MHz}, \mathrm{DMSO}-d_{6}\right) \delta 9.76(\mathrm{~s}, 1 \mathrm{H}), 7.41-7.25(\mathrm{~m}, 4 \mathrm{H}), 7.13(\mathrm{~d}, J=8.4$ $\mathrm{Hz}, 2 \mathrm{H}), 6.72(\mathrm{~d}, J=8.7 \mathrm{~Hz}, 2 \mathrm{H}), 6.61(\mathrm{~d}, J=3.6 \mathrm{~Hz}, 1 \mathrm{H}), 6.30(\mathrm{~d}, J=3.6 \mathrm{~Hz}, 1 \mathrm{H}), 3.23(\mathrm{~s}, 3 \mathrm{H}), 2.15(\mathrm{~s}$, $3 \mathrm{H}) ;{ }^{13} \mathrm{C}-\mathrm{NMR}\left(126 \mathrm{MHz}\right.$, DMSO- $\left.d_{6}\right) \delta 157.95,157.94,155.1,145.4,142.8,135.2,131.1,128.16,128.13$, $127.3,125.6,120.4,118.3,115.5,104.5,36.8,16.9$.

5-(2-Chloro-4-hydroxyphenyl)- $N$-methyl- $N$-(o-tolyl)furan-2-carboxamide 5<smiles>Cc1ccccc1N(C)C(=O)c1ccc(-c2ccc(O)cc2Cl)o1</smiles>

The title compound was prepared by reaction of $\mathbf{5 a}(120 \mathrm{mg}, 0.34 \mathrm{mmol})$ and $\mathrm{BF}_{3} \cdot \mathrm{SMe}_{2}(265 \mu \mathrm{L}, 2.04$ mmol) according to method $\mathrm{C}$. The residue was purified by silica gel column chromatography ( $n$ hexane/ethyl acetate 60:40) to afford the desired product as white solid (89 mg, 77\%). $\mathrm{C}_{19} \mathrm{H}_{16} \mathrm{ClNO}_{3}$; $\mathrm{MW}$ 342; mp: 198-201 ${ }^{\circ} \mathrm{C}$; MS (ESI) 342, $344[\mathrm{M}+\mathrm{H}]^{+}$; ${ }^{1} \mathrm{H}-\mathrm{NMR}\left(500 \mathrm{MHz}, \mathrm{DMSO}-d_{6}\right) \delta 10.27$ (s, 1H), $7.42-$ $7.26(\mathrm{~m}, 4 \mathrm{H}), 6.85(\mathrm{~d}, J=2.4 \mathrm{~Hz}, 1 \mathrm{H}), 6.83-6.78(\mathrm{~m}, 2 \mathrm{H}), 6.69(\mathrm{dd}, J=8.7,2.5 \mathrm{~Hz}, 1 \mathrm{H}), 6.36(\mathrm{~d}, J=3.7$ $\mathrm{Hz}, 1 \mathrm{H}), 3.24$ (s, 3H), 2.15 (s, 3H); ${ }^{13} \mathrm{C}-\mathrm{NMR}\left(126 \mathrm{MHz}, \mathrm{DMSO}-d_{6}\right) \delta$ 158.2, 157.7, 151.0, 145.6, 142.7, 135.2, 131.2, 130.2, 129.2, 128.2, 128.1, 127.4, 118.5, 117.9, 116.8, 114.7, 109.7, 36.9, 16.9; IR $\left(\mathrm{cm}^{-1}\right)$ 3064, 2993, 2877, 2775, 2691, 1562.

5-(2-Fluoro-4-hydroxyphenyl)- $N$-methyl- $N$-(o-tolyl)furan-2-carboxamide 6<smiles>Cc1ccccc1N(C)C(=O)c1ccc(-c2ccc(O)cc2F)o1</smiles>

The title compound was prepared by reaction of $6 \mathrm{a}(57 \mathrm{mg}, 0.17 \mathrm{mmol})$ and $\mathrm{BF}_{3} \cdot \mathrm{SMe}_{2}(110 \mu \mathrm{L}, 1.01 \mathrm{mmol})$ according to method $\mathrm{C}$. The residue was purified by silica gel column chromatography ( $n$-hexane/ethyl acetate 60:40) to afford the desired product as yellow oil (10 mg, 18\%). $\mathrm{C}_{19} \mathrm{H}_{16} \mathrm{FNO}_{3}$; MW 325; MS (ESI) $326[\mathrm{M}+\mathrm{H}]^{+}$; ${ }^{1} \mathrm{H}-\mathrm{NMR}\left(500 \mathrm{MHz}, \mathrm{DMSO}-d_{6}\right) \delta 10.29(\mathrm{~s}, 1 \mathrm{H}), 7.42-7.26(\mathrm{~m}, 4 \mathrm{H}), 6.82(\mathrm{t}, J=8.8 \mathrm{~Hz}, 1 \mathrm{H})$, $6.62(\mathrm{dd}, J=13.1,2.3 \mathrm{~Hz}, 1 \mathrm{H}), 6.58(\mathrm{dd}, J=8.6,2.4 \mathrm{~Hz}, 1 \mathrm{H}), 6.50(\mathrm{t}, J=3.6 \mathrm{~Hz}, 1 \mathrm{H}), 6.35(\mathrm{~d}, J=3.6 \mathrm{~Hz}$, $1 \mathrm{H}), 3.24(\mathrm{~s}, 3 \mathrm{H}), 2.15(\mathrm{~s}, 3 \mathrm{H}) ;{ }^{13} \mathrm{C}-\mathrm{NMR}\left(126 \mathrm{MHz}, \mathrm{DMSO}-d_{6}\right) \delta 160.2,159.3,159.2,158.2,157.7,149.23$, $145.5,142.7,135.2,131.1,128.2,128.1,127.4,126.9,126.8,118.2,112.02,108.5,108.45,108.40,108.3$, $103.2,103.0,36.9,16.9$.

5-(3-Fluoro-4-hydroxyphenyl)- $N$-methyl- $N$-(o-tolyl)furan-2-carboxamide 7 
<smiles>Cc1ccccc1N(C)C(=O)c1ccc(-c2ccc(O)c(F)c2)o1</smiles>

The title compound was prepared by reaction of $7 \mathbf{a}(60 \mathrm{mg}, 0.18 \mathrm{mmol})$ and $\mathrm{BF}_{3} \cdot \mathrm{SMe}_{2}(110 \mu \mathrm{L}, 1.06 \mathrm{mmol})$ according to method $\mathrm{C}$. The residue was purified by silica gel column chromatography ( $n$-hexane/ethyl acetate 60:40) to afford the desired product as yellow solid (55 mg, 95\%). $\mathrm{C}_{19} \mathrm{H}_{16} \mathrm{FNO}_{3}$; MW 325; mp: 190$192{ }^{\circ} \mathrm{C}$; MS (ESI) $326[\mathrm{M}+\mathrm{H}]^{+}$; ${ }^{1} \mathrm{H}-\mathrm{NMR}\left(500 \mathrm{MHz}, \mathrm{DMSO}-d_{6}\right) \delta 10.22(\mathrm{~s}, 1 \mathrm{H}), 7.42-7.26(\mathrm{~m}, 4 \mathrm{H}), 7.00$ $-6.92(\mathrm{~m}, 2 \mathrm{H}), 6.89(\mathrm{t}, J=8.8 \mathrm{~Hz}, 1 \mathrm{H}), 6.73(\mathrm{~d}, J=3.6 \mathrm{~Hz}, 1 \mathrm{H}), 6.44(\mathrm{~d}, J=3.6 \mathrm{~Hz}, 1 \mathrm{H}), 3.24(\mathrm{~s}, 3 \mathrm{H}), 2.15$ $(\mathrm{s}, 3 \mathrm{H}) ;{ }^{13} \mathrm{C}-\mathrm{NMR}\left(126 \mathrm{MHz}, \mathrm{DMSO}-d_{6}\right) \delta 157.7,153.7,151.9,150.0,146.0,145.4,145.3,142.8,135.2$, $131.1,128.2$, 128.1 127.3, 121.0, 120.9, 120.68, 120.65, 118.4, 118.02, 118.00, 111.9, 111.8, 105.8, 36.9, 16.9 .

5-(3-Chloro-4-hydroxyphenyl)- $N$-methyl- $N$-(o-tolyl)furan-2-carboxamide 8<smiles>Cc1ccccc1N(C)C(=O)c1ccc(-c2ccc(O)c(Cl)c2)o1</smiles>

The title compound was prepared by reaction of $\mathbf{1 b}(80 \mathrm{mg}, 0.27 \mathrm{mmol})$, (3-chloro-4-hydroxyphenyl) boronic acid (61 mg, $0.35 \mathrm{mmol})$, cesium carbonate $(266 \mathrm{mg}, 0.82 \mathrm{mmol})$ and tetrakis(triphenylphoshine) palladium ( $6 \mathrm{mg}, 0.02$ eq.) according to method B. The residue was purified by crystallization in ethanol and water, to afford the desired product as white solid (36 mg, 39\%). $\mathrm{C}_{19} \mathrm{H}_{16} \mathrm{ClNO}_{3} ; \mathrm{MW} 342 ; \mathrm{mp}: 77-80$ ${ }^{\circ} \mathrm{C}$; MS (ESI) 342, $344[\mathrm{M}+\mathrm{H}]^{+}$; ${ }^{1} \mathrm{H}-\mathrm{NMR}\left(500 \mathrm{MHz}, \mathrm{DMSO}-d_{6}\right) \delta 10.53(\mathrm{~s}, 1 \mathrm{H}), 7.43-7.26(\mathrm{~m}, 4 \mathrm{H}), 7.14$ $(\mathrm{dd}, J=8.5,2.2 \mathrm{~Hz}, 1 \mathrm{H}), 7.08(\mathrm{~d}, J=2.2 \mathrm{~Hz}, 1 \mathrm{H}), 6.90(\mathrm{~d}, J=8.5 \mathrm{~Hz}, 1 \mathrm{H}), 6.75(\mathrm{~d}, J=3.6 \mathrm{~Hz}, 1 \mathrm{H}), 6.50$ $(\mathrm{d}, J=3.6 \mathrm{~Hz}, 1 \mathrm{H}), 3.24(\mathrm{~s}, 3 \mathrm{H}), 2.15(\mathrm{~s}, 3 \mathrm{H}) ;{ }^{13} \mathrm{C}-\mathrm{NMR}\left(126 \mathrm{MHz}, \mathrm{DMSO}-d_{6}\right) \delta 157.7,153.43,153.42$, 146.0, 142.7, 135.2, 131.0, 128.3, 128.0, 127.3, 125.2, 124.0, 121.5, 120.2, 118.5, 116.8, 105.7, 36.9, 16.9.

5-(3,5-Difluoro-4-hydroxyphenyl)- $N$-methyl- $N$-(o-tolyl)furan-2-carboxamide 9<smiles>Cc1ccccc1N(C)C(=O)c1ccc(-c2cc(F)c(O)c(F)c2)o1</smiles>

The title compound was prepared by reaction of $9 \mathrm{a}(180 \mathrm{mg}, 0.50 \mathrm{mmol})$ and $\mathrm{BF}_{3} \cdot \mathrm{SMe}_{2}(320 \mu \mathrm{L}, 3.00$ mmol) according to method $\mathrm{C}$. The residue was purified by silica gel column chromatography ( $n$ hexane/ethyl acetate 60:40) to afford the desired product as yellow solid (140 mg, 81\%). $\mathrm{C}_{19} \mathrm{H}_{15} \mathrm{~F}_{2} \mathrm{NO}_{3}$; MW 343; mp: 176-178 ${ }^{\circ} \mathrm{C}$; MS (ESI) $344[\mathrm{M}+\mathrm{H}]^{+}$; ${ }^{1} \mathrm{H}-\mathrm{NMR}\left(500 \mathrm{MHz}\right.$, acetone- $\left.d_{6}\right) \delta 9.25(\mathrm{~s}, 1 \mathrm{H}), 7.30-7.42$ $(\mathrm{m}, 4 \mathrm{H}), 6.88(\mathrm{~d}, J=7 \mathrm{~Hz}, 2 \mathrm{H}), 6.75(\mathrm{~d}, J=3 \mathrm{~Hz}, 1 \mathrm{H}), 6.59(\mathrm{~d}, J=3 \mathrm{~Hz}, 1 \mathrm{H}), 3.31(\mathrm{~s}, 3 \mathrm{H}), 2.22(\mathrm{~s}, 3 \mathrm{H}) ;{ }^{13} \mathrm{C}-$ NMR $\left(126 \mathrm{MHz}\right.$, acetone- $\left.d_{6}\right) \delta 158.9,154.55,154.50,153.9,152.6,152.5,148.4,144.3,136.8,135.2,135.0$, $134.9,132.2,129.3,129.2,128.4,122.1,122.0,121.9,119.3,108.7,108.6,108.5,108.4,107.5,37.5,17.6$; IR $\left(\mathrm{cm}^{-1}\right) 3056,2930,1623$. 
<smiles>Cc1ccccc1N(C)C(=O)c1ccc(-c2cc(Cl)c(O)c(Cl)c2)o1</smiles>

The title compound was prepared by reaction of $\mathbf{1 0 a}(240 \mathrm{mg}, 0.61 \mathrm{mmol})$ and $\mathrm{BF}_{3} \cdot \mathrm{SMe}_{2}(476 \mu \mathrm{L}, 3.66$ mmol) according to method $\mathrm{C}$. The residue was purified by silica gel column chromatography ( $n$ hexane/ethyl acetate 60:40) to afford the desired product as orange solid (117 mg, 51\%). $\mathrm{C}_{19} \mathrm{H}_{15} \mathrm{Cl}_{2} \mathrm{NO}_{3}$; MW 376; mp: 134-137 ${ }^{\circ} \mathrm{C}$; MS (ESI) 376, $378[\mathrm{M}+\mathrm{H}]^{+} ;{ }^{1} \mathrm{H}-\mathrm{NMR}\left(500 \mathrm{MHz}\right.$, acetone- $\left.d_{6}\right) \delta 9.08(\mathrm{~s}, 1 \mathrm{H})$, 7.34-7.43 (m, 3H), $7.30(\mathrm{~d}, J=8 \mathrm{~Hz}, 1 \mathrm{H}), 7.19(\mathrm{~s}, 2 \mathrm{H}), 6.80(\mathrm{~d}, J=3 \mathrm{~Hz}, 1 \mathrm{H}), 6.71(\mathrm{~d}, J=3 \mathrm{~Hz}, 1 \mathrm{H}), 3.31$ $(\mathrm{s}, 3 \mathrm{H}), 2.23(\mathrm{~s}, 3 \mathrm{H}) ;{ }^{13} \mathrm{C}-\mathrm{NMR}\left(126 \mathrm{MHz}\right.$, acetone- $\left.d_{6}\right) \delta 158.9,153.2,150.0,148.6,144.3,136.7,132.2$, 129.5, 129.1, 128.3, 125.0, 124.1, 123.4, 119.4, 107.5, 37.5, 17.6; IR $\left(\mathrm{cm}^{-1}\right) 3129,2957,2923,2853,1620$.

\section{b) Biological methods}

[2,4,6,7- $\left.{ }^{3} \mathrm{H}\right]$-E2 and $\left[2,4,6,7-{ }^{3} \mathrm{H}\right]$-E1 were purchased from Perkin-Elmer, Boston. Quickszint Flow 302 scintillator fluid was bought from Zinsser Analytic, Frankfurt. Other chemicals were purchased from Sigma, Roth or Merck.

$\boldsymbol{h} 17 \boldsymbol{\beta}$-HSD1 and $\boldsymbol{h} 17 \boldsymbol{\beta}$-HSD2 enzyme preparation. Cytosolic $(h 17 \beta$-HSD1) and microsomal $(h 17 \beta$ HSD2) fractions were obtained from human placenta according to previously described procedures. ${ }^{1-5}$ Fresh tissue was homogenized and the enzymes were separated from the mitochondria, cell membrane, nucleus and other rests by fractional centrifugation at $1000 \mathrm{~g}, 10.000 \mathrm{~g}$ and $150.000 \mathrm{~g}$. The pellet fraction containing the microsomal $h 17 \beta$-HSD2 was used for the determination of $h 17 \beta$-HSD2 inhibition, while $h 17 \beta$-HSD1 was obtained after precipitation with ammonium sulfate from the cytosolic fraction for use of testing of $h 17 \beta$-HSD1 inhibition. Aliquots containing $h 17 \beta$-HSD1 or $h 17 \beta$-HSD2 were stored frozen.

Inhibition of $\boldsymbol{h 1 7} \boldsymbol{\beta}$-HSD2 in cell-free assay. Inhibitory activities were evaluated following an established method with minor modifications. ${ }^{6,7}$ Briefly, the enzyme preparation was incubated with $\mathrm{NAD}^{+}[1500 \mu \mathrm{M}]$ in the presence of potential inhibitors at $37{ }^{\circ} \mathrm{C}$ in a phosphate buffer $(50 \mathrm{mM})$ supplemented with $20 \%$ of glycerol and EDTA $1 \mathrm{mM}$. Inhibitor stock solutions were prepared in DMSO. Final concentration of DMSO was adjusted to $1 \%$ in all samples. The enzymatic reaction was started by addition of a mixture of unlabelledand $\left[{ }^{3} \mathrm{H}\right]$-E2 (final concentration: $500 \mathrm{nM}, 0.11 \mu \mathrm{Ci}$ ) at $37^{\circ} \mathrm{C}$. After $20 \mathrm{~min}$, the incubation was stopped with $\mathrm{HgCl}_{2}$ and the mixture was extracted with ether. After evaporation, the steroids were dissolved in acetonitrile/water (45:55). E1 and E2 were separated using acetonitrile/water (45:55) as mobile phase in a C18 RP chromatography column (Nucleodur C18, $3 \mu \mathrm{m}$, Macherey-Nagel, Düren) connected to a HPLCsystem (Agilent 1100 Series, Agilent Technologies, Waldbronn). Detection and quantification of the steroids were performed using a radioflow detector (Berthold Technologies, Bad Wildbad). The conversion rate was calculated according to the following equation: $\%$ conversion $=(\% \mathrm{E} 1 /(\% \mathrm{E} 1+\% \mathrm{E} 2)) \times 100$. Each value was calculated from at least two independent experiments. 


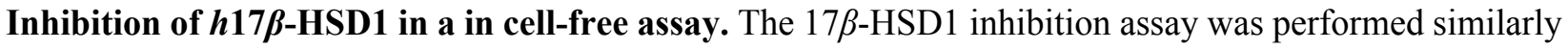
to the $h 17 \beta$-HSD2 test. The human cytosolic enzyme was incubated with NADH [500 $\mu \mathrm{M}$ ] while the rat recombinant enzyme was reacted with NADPH $[500 \mu \mathrm{M}]$. Test compound and a mixture of unlabelled- and $\left[{ }^{3} \mathrm{H}\right]$-E1 (final concentration: $500 \mathrm{nM}, 0.15 \mu \mathrm{Ci}$ ) were added and mixed for $10 \mathrm{~min}$ at $37^{\circ} \mathrm{C}$. Further treatment of the samples and HPLC separation was carried out as mentioned above for $h 17 \beta$-HSD2.

Estrogen receptor affinity in a cell-free assay. The binding affinity of compound 1 to ER $\alpha$ and $E R \beta$ was determined according to the recommendations of the US Environmental Protection Agency (EPA) by their Endocrine Disruptor Screening Program (EDSP) ${ }^{8}$ using recombinant human proteins. Briefly, $1 \mathrm{nM}$ of ER $\alpha$ and $4 \mathrm{nM}$ of ER $\beta$, respectively, were incubated with $\left[{ }^{3} \mathrm{H}\right]-\mathrm{E} 2$ ( $3 \mathrm{nM}$ for $\mathrm{ER} \alpha$ and $10 \mathrm{nM}$ for ER $\beta$ ) and test compound $(3 \mu \mathrm{M}$ for $\mathrm{ER} \alpha$ and $10 \mu \mathrm{M}$ for $\mathrm{ER} \beta)$ for $16-20 \mathrm{~h}$ at $4^{\circ} \mathrm{C}$.

The potential inhibitors were dissolved in DMSO ( $2 \%$ final concentration). Evaluation of non-specificbinding was performed with unlabeled E2 at concentrations 100-fold of [ $\left.{ }^{3} \mathrm{H}\right]-\mathrm{E} 2(300 \mathrm{nM}$ for ER $\alpha$ and 1000 $\mathrm{nM}$ for $\mathrm{ER} \beta$ ). After incubation, ligand-receptor complexes were selectively bound to hydroxyapatite (83.5 $\mathrm{g} /$ LinTE-buffer). The bound complex was washed three times and resuspended in ethanol. For radiodetection, scintillator cocktail (Quickszint 212, Zinsser Analytic, Frankfurt) was added and samples were measured in a liquid scintillation counter (1450 LSC \& Luminescence Counter, Perkin Elmer).

From these results the percentage of $\left[{ }^{3} \mathrm{H}\right]-\mathrm{E} 2$ displacement by the compounds was calculated. The plot of $\%$ displacement versus compound concentration resulted in sigmoidal binding curves. The compound concentrations necessary to displace $50 \%$ of the receptor bound $\left[{ }^{3} \mathrm{H}\right]-\mathrm{E} 2$ were determined. Unlabeled E2 $\mathrm{IC}_{50}$ values were determined in each experiment and used as reference. The $\mathrm{E} 2 \mathrm{IC}_{50}$ determined were $3 \pm 20 \%$ $\mathrm{nM}$ for $E R \alpha$ and $10 \pm 20 \% \mathrm{nM}$ for $\mathrm{ER} \beta$.Relative Binding Affinity was determined by applying the following equation: $\mathrm{RBA}[\%]=\left(\mathrm{IC}_{50}(\mathrm{E} 2) / \mathrm{IC}_{50}\right.$ (compound $) \cdot 100 .{ }^{10}$ This results in a RBA value of $100 \%$ for E2. After the assay was established and validated, a modification was made to increase throughput. Compounds were tested at concentrations of 1000 times the $\mathrm{IC}_{50}(\mathrm{E} 2)$. Compounds with less than $50 \%$ displacement of $\left[{ }^{3} \mathrm{H}\right]$ $\mathrm{E} 2$ at a concentration of 1000 times $\mathrm{IC}_{50}(\mathrm{E} 2)$ were classified as $\mathrm{RBA}<0.1 \%$.

Metabolic stability in a cell-free assay. Compound $\mathbf{1}$ was tested according to established method ${ }^{9-11}$ For evaluation of phase I and II metabolic stability $1 \mu \mathrm{M}$ compound was incubated with $1 \mathrm{mg} / \mathrm{ml}$ pooled mammalian liver S9 fraction (BD Gentest), $2 \mathrm{mM}$ NADPH regenerating system, $1 \mathrm{mM}$ UDPGA and 0.1 $\mathrm{mM}$ PAPS at $37^{\circ} \mathrm{C}$ for $0,5,15$ and 60 minutes at a final volume of $100 \mu \mathrm{L}$. The incubation was stopped by precipitation of S9 enzymes with 2 volumes of cold acetonitrile containing internal standard. Concentration of the remaining test compound at the different time points was analyzed by LC-MS/MS and used to determine half-life $\left(\mathrm{t}_{1 / 2}\right)$.

MTT-Cytotoxicity assay. The number of living cells was evaluated measuring the reduction of 3-(4,5dimethylthiazol-2-yl)-2,5-diphenyltetrazoliumbromide (MTT). Experiments were performed in 96-well cell culture plates in DMEM supplemented with 10\% FCS. Cells were incubated for $66 \mathrm{~h}$ with $6.25,12.50,25$, 50 , and $100 \mu \mathrm{M}$ of test compound at $37{ }^{\circ} \mathrm{C}$ in a humidified atmosphere at $5 \% \mathrm{CO}_{2}$. For cleavage reaction MTT-solution $(5 \mathrm{mg} / \mathrm{mL}$ in PBS) was added and incubation was continued for another $66 \mathrm{~h}$. Reaction stop and cell lysis were carried out by addition of sodium dodecyl sulphate (SDS) in $0.01 \mathrm{~N} \mathrm{HCl} \mathrm{(10 \% ).} \mathrm{The}$ produced blue formazan was quantified spectrophotometrically at $590 \mathrm{~nm}$ as described by Denizot and Lang ${ }^{12}$ with minor modifications. 
Cell culture. The human NSCLC cell line Calu-1 (squamous cell carcinoma) was purchased from the American Type Culture Collection (Rockville, MD). Cells were routinely maintained in RPMI 1640 medium, supplemented with 10\% heat-inactivated fetal bovine serum (FBS), $2 \mathrm{mM}$ glutamine and penicillinstreptomycin-amphotericin B solution (10,000 units penicillin, $10 \mathrm{mg}$ streptomycin and $25 \mu \mathrm{g}$ amphotericin $\mathrm{B} / \mathrm{mL}$ ). Sigma-Aldrich Co. (St. Louis, $\mathrm{MO}$ ) at $37^{\circ} \mathrm{C}$ in a humidified incubator with $5 \% \mathrm{CO}_{2}$. Prior to all experiments, cells were grown overnight in a phenol red-free RPMI 1640 medium, supplemented with 10\% charcoal-dextran-stripped FBS, Sigma-Aldrich Co. (St. Louis, MO). The stock solutions of 1 (5.43 mM) and estrone (E1) $(7 \mathrm{mg} / \mathrm{ml})$ were prepared in DMSO, aliquoted and stored at $-20^{\circ} \mathrm{C}$ until use. The investigated compounds were diluted in the culture medium to the desired concentration $(50 \mathrm{nM}$ or $500 \mathrm{nM}$ for 1 and $5 \mu \mathrm{M}$ for E1) and added to cell cultures during all experiments. The same volume of DMSO was used as a vehicle control and its final concentration in culture medium never exceeded $0.1 \%$.

Impact of E1 and 1 treatment on Calu-1 cells growth in real time conditions. The xCELLigence RTCA DP System, ACEA Biosciences (San Diego, CA), with 16-well E-Plates was employed for label-free, realtime monitoring of cell proliferation. It is an electrical impedance-based cell proliferation assay, where the impedance values from microelectrodes located at the bottom of each well in E-plate are measured and converted by the software into the Cell Index. Therefore, when cells adhere to the well surface and start to proliferate, the change in electrode impedance is recorded. At the beginning of the experiment $150 \mu \mathrm{L}$ of phenol red-free RPMI 1640, supplemented with $10 \%$ charcoal-dextran-stripped FBS was added to each well and the background impedance was measure after 30 minutes of incubation. Next, Calu- 1 cells were harvested by a standard trypsinization method, counted automatically with EVETM cell counter; NanoEnTek Inc. (Seoul, Korea), suspended in a phenol red-free RPMI 1640 medium, supplemented with $10 \%$ charcoal-dextran-stripped FBS and seeded into 16-well E-Plates at a concentration of 3,5 $10^{3}$ cells/well to a final volume of $200 \mu \mathrm{l}$ per well. In order to avoid evaporation of medium, water was added to the spaces between all wells. The E-plate was allowed to incubate at room temperature for 30 minutes and then was inserted into the xCELLigence RTCA DP device for continuous recording of impedance overnight. The next day culture media were changed and for another $50 \mathrm{hrs}$ Calu-1 cells were cultured in the following experimental groups: (1) control - medium alone (phenol red-free RPMI 1640 medium, supplemented with 10\% charcoal-dextran-stripped FBS), (2) medium with 1 at the concentration of $50 \mathrm{nM}$, (3) medium with 1 at the concentration of $500 \mathrm{nM}$, (4) vehicle control - medium with DMSO. Afterwards, media were replaced once again and cells were exposed to the compounds for $75 \mathrm{hrs}$ of incubation in the following groups: (1) 5 $\mu \mathrm{M} \mathrm{E1}$, (2) $5 \mu \mathrm{M} \mathrm{E} 1$ and $50 \mathrm{nM}$ 1, (3) $5 \mu \mathrm{M} \mathrm{E1}$ and $500 \mathrm{nM}$ 1, (4) vehicle control - medium with DMSO. Cell growth in real time was monitored from the beginning of an experiment till $150 \mathrm{~h}$ and the electrical impedance was measured at 15-minutes intervals throughout the cultivation period. Cell index was normalized (normalized cell index) at the time point of E1 and 1 administration using software provided by the manufacturer (RTCA Software, v. 1.2, November 2009). Four replicates of each compound concentration for Calu-1 cell line were used. 


\section{c) Computational Details}

Docking simulations. As a first step, the Restrained ElectroStatic Potential (RESP) charges ${ }^{13}$ were computed for 1 to enhance the accuracy of the following docking simulations. In particular, 1 was optimized at the Density Functional Theory level using the hybrid B3LYP functional ${ }^{14}$ and the Pople6-311++G(d,p) basis set. Molecular electrostatic potential (MEP) was thus computed on such structure, at Hartree-Fock (HF) level of theory, using a smaller basis set $(6-31 G(d))$. Finally, the charge values were fitted in order to reproduce the computed MEPs. All these calculations were performed with the Gaussian $09^{15}$ package apart from the charges fitting performed using Antechamber, a freely accessible AmberTools program. Next, docking simulations were performed on the crystal structure of a ternary complex ( $h 17 \beta$-HSD1- inhibitor$\mathrm{NADP}+$ available from PDB with code $3 \mathrm{HB} 5^{16}$ ). The $3 \mathrm{HB} 5 \mathrm{X}$-ray solved structure was first pre-treated using the protein preparation module of Schrodinger suite 2015-3 ${ }^{17}$, which enables to add missing hydrogen atoms and to determine the optimal protonation states for histidine residues. The obtained structure was used for docking simulations performed by GLIDE v6.8, ${ }^{18}$ which is part of the Schrodinger Suite. During the docking process, the receptor protein was held fixed, while full conformational flexibility was allowed for the ligand. The described protocol was performed employing the default Force Field OPLS_2005, except for the atomic charges, which were derived following the RESP protocol, as described above. A cubic grid set on the center of mass of the cognate ligand having an edge of $13 \AA$ for the inner box and of $30 \AA$ for the outerbox was used. All simulations were performed flagging the extra precision (XP) mode. In order to ensure an adequate sampling of the conformational space, 20000 poses per ligand were generated in the initial phase and, among them, 10000 were selected for post-docking minimization. Note that docking simulations were performed including NADPH as cofactor, given its occurrence at much higher concentration with respect to NADP+ in living cells. ${ }^{19}$ The herein described protocol was set on the basis of docking calibration studies aimed at reproducing the X-ray pose of the $3 \mathrm{HB} 5$ cognate ligand.

All the docking parameters employed in our studies were initially calibrated trying to reproduce as good as possible the X-ray binding conformation of the cognate ligand (i.e., $3\{[$ (9beta,14beta,16alpha,17alpha)3,17-dihydroxyestra-1,3,5(10)-trien-16-yl]methyl b benzamide, hereafter referred to as E2B) embedded into 3HB5 available from PDB. In this respect, Figure S1 shows unequivocally the goodness of the superimposition between docking and X-ray poses showing a value of root-mean-square deviation (RMSD) equal to $0.64 \AA$.

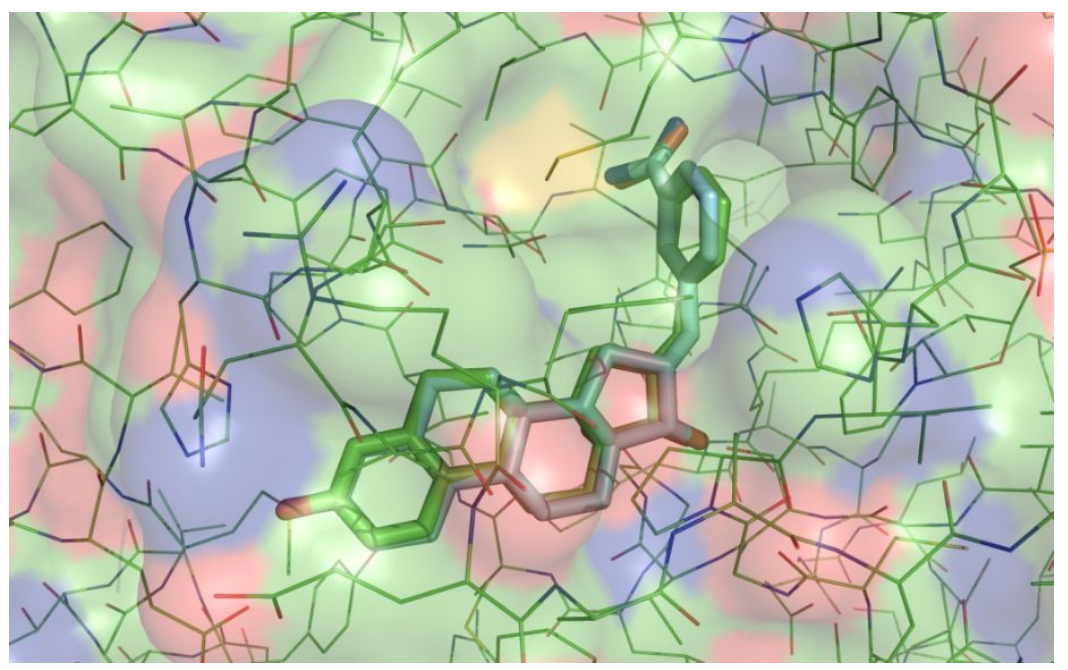


Figure S1. Crystal structure pose (in green) and top-scored docking pose (in cyan) of E2B in the ternary complex of $h 17 \beta$-HSD1 (PDB code: 3 HB5).

Density functional theory. All DFT calculations were carried out using the Gaussian 09 package. ${ }^{15}$ Geometry optimizations were performed at the B3LYP $2 / 6-311++\mathrm{G}(\mathrm{d}, \mathrm{p})$ level of theory. In order to take into account, the solvation effect, all calculations were carried out using the polarizable continuum model (PCM) for water, as implemented in Gaussian 09.

Model validation. The robustness of the found correlation was challenged by performing a randomization analysis. In order to assess the risk of chance correlation 1 million of y-scrambled models were generated and for each of them the value of $\mathrm{r}^{2}$ was computed. Notably, the found correlation can be considered statistically significant if for all the randomized models a value of $\mathrm{r}^{2}$ lower that that observed for the nonrandomized model is detected (Figure S2).

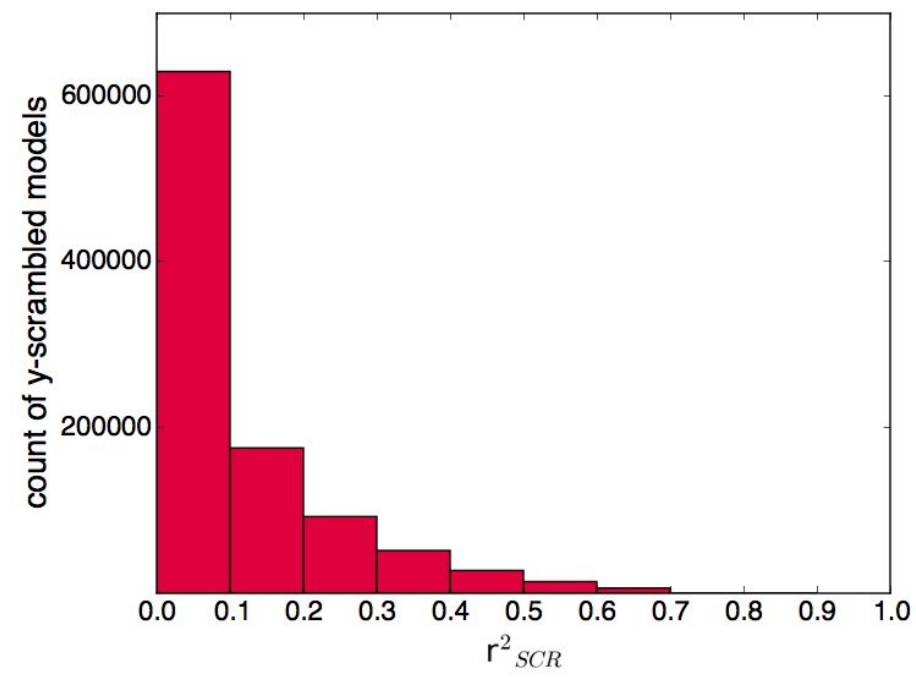

Figure S2. Histogram of $\mathrm{r}^{2}{ }_{\mathrm{SCR}}$ VS. number of randomized models over 1 million y-scrambling runs. 


\section{d) Representative ${ }^{1} \mathrm{H}-\mathrm{NMR}$ and ${ }^{13} \mathrm{C}$-NMR spectra}

\section{Compound 1:}

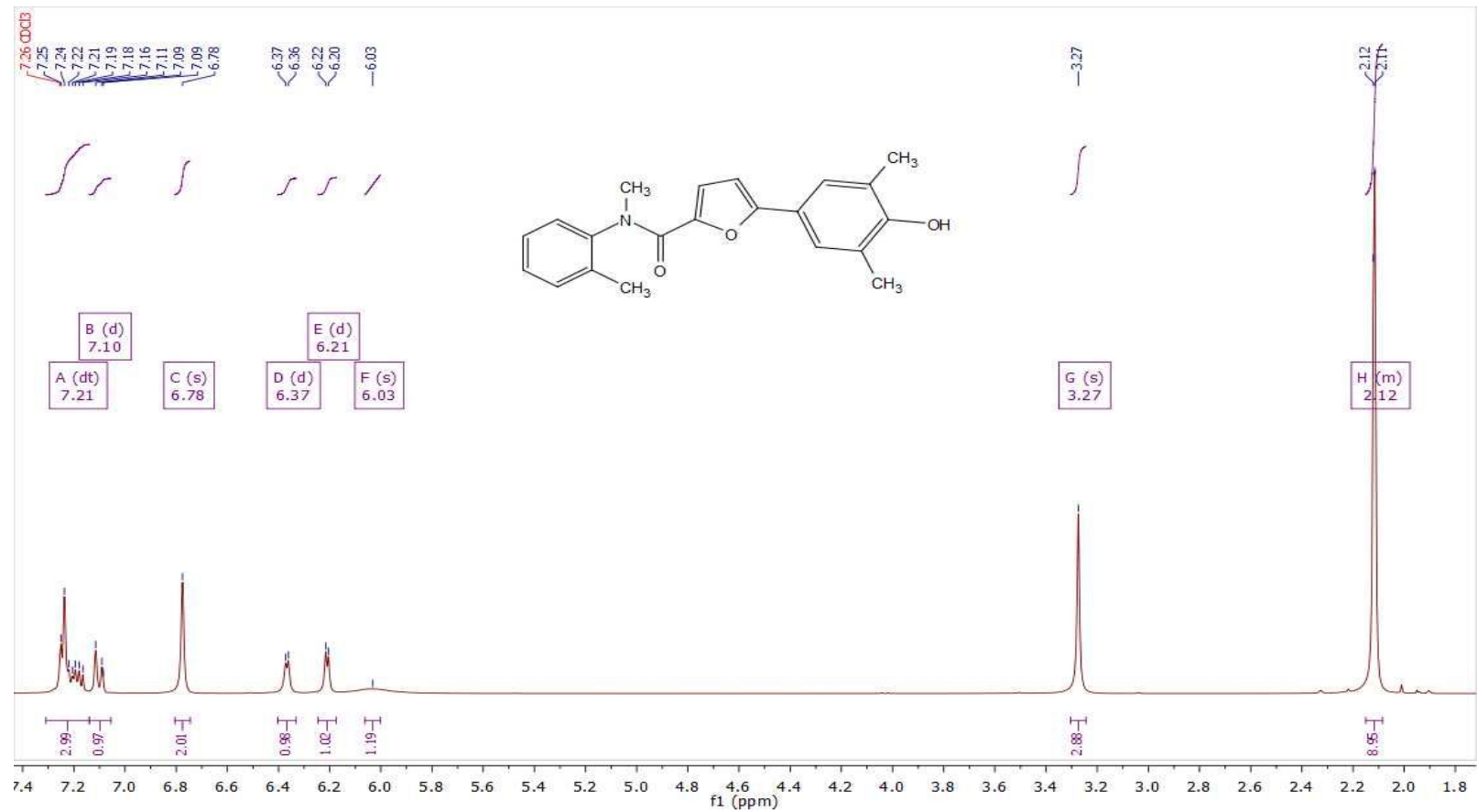

${ }^{1} \mathrm{H}$ NMR $(300 \mathrm{MHz}$, Chloroform-d) $\delta 7.21$ (dt, $J=16.6,4.3 \mathrm{~Hz}, 3 \mathrm{H}), 7.10(\mathrm{~d}, J=7.3 \mathrm{~Hz}, 1 \mathrm{H}), 6.78(\mathrm{~s}, 2 \mathrm{H}), 6.37(\mathrm{~d}, J=3.6 \mathrm{~Hz}, 1 \mathrm{H}), 6.21(\mathrm{~d}$, $J=3.5 \mathrm{~Hz}, 1 \mathrm{H}), 6.03(\mathrm{~s}, 1 \mathrm{H}), 3.27(\mathrm{~s}, 3 \mathrm{H}), 2.15-2.08(\mathrm{~m}, 9 \mathrm{H})$.

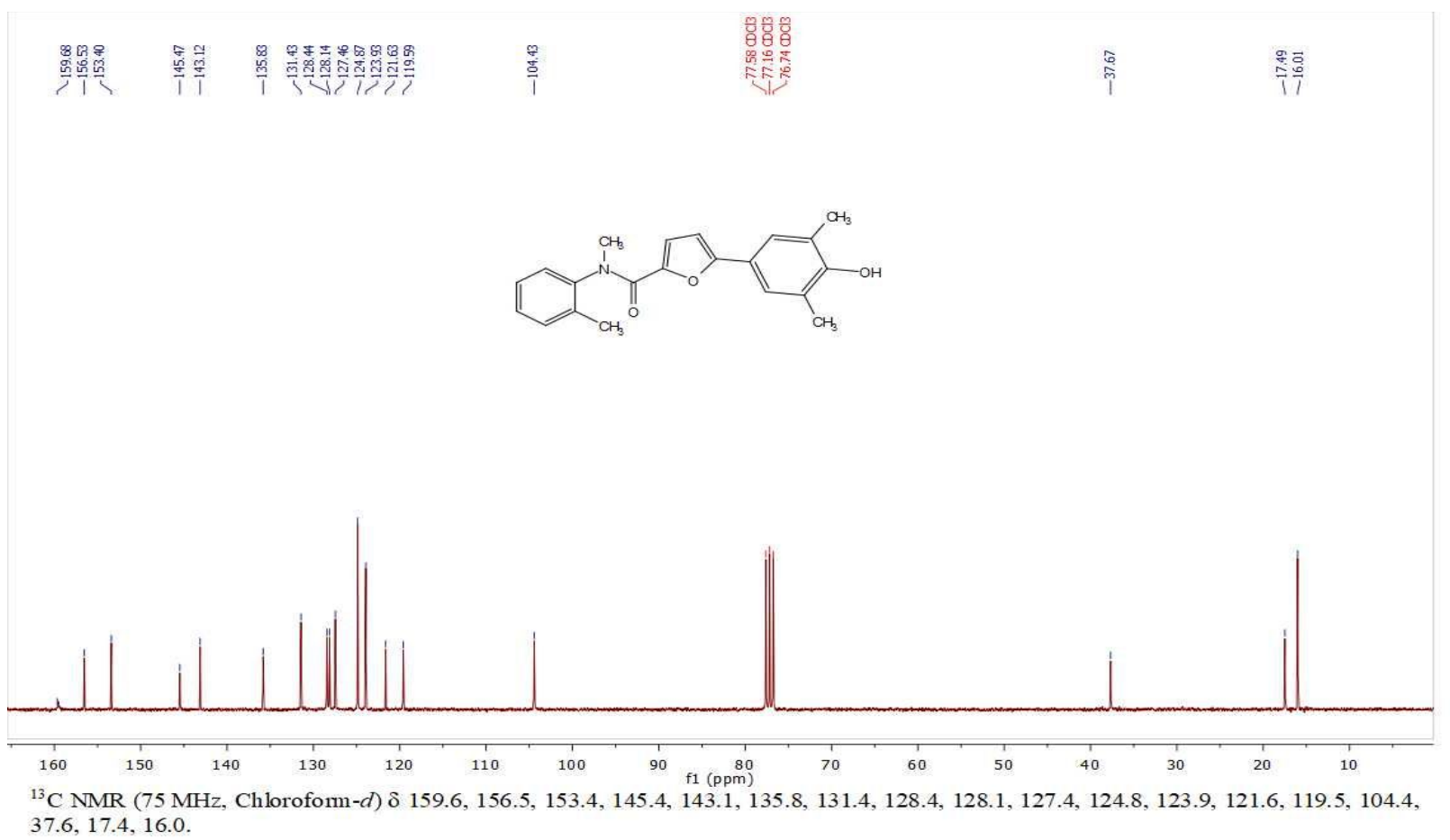




\section{Compound 4:}

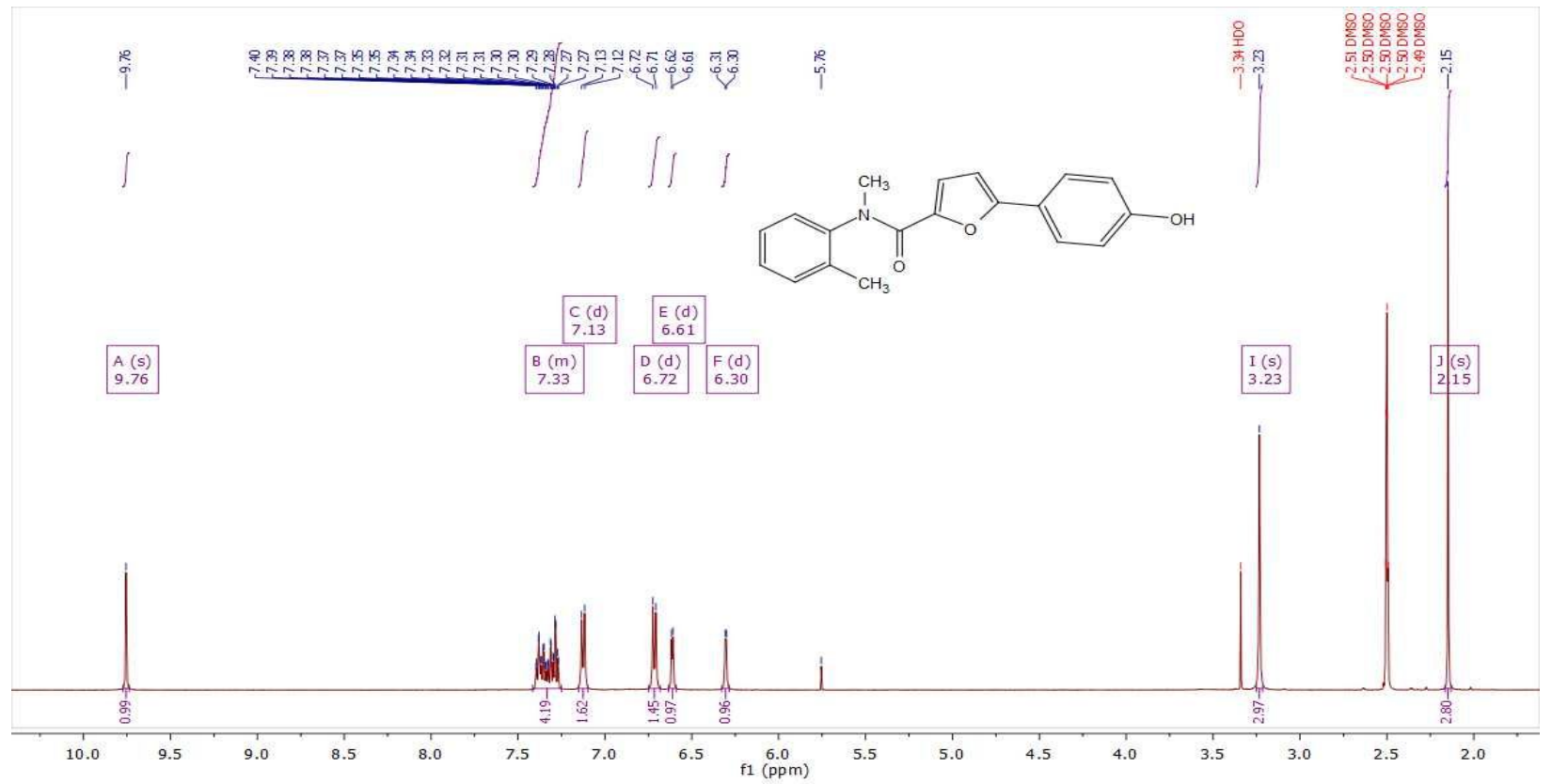

${ }^{1} \mathrm{H}$ NMR $\left(500 \mathrm{MHz}, \mathrm{DMSO}-d_{6}\right) \delta 9.76(\mathrm{~s}, 1 \mathrm{H}), 7.41-7.25(\mathrm{~m}, 4 \mathrm{H}), 7.13(\mathrm{~d}, J=8.4 \mathrm{~Hz}, 2 \mathrm{H}), 6.72(\mathrm{~d}, J=8.7 \mathrm{~Hz}, 1 \mathrm{H}), 6.61(\mathrm{~d}, J=3.6 \mathrm{~Hz}$, $1 \mathrm{H}), 6.30(\mathrm{~d}, J=3.6 \mathrm{~Hz}, 1 \mathrm{H}), 3.23(\mathrm{~s}, 3 \mathrm{H}), 2.15(\mathrm{~s}, 3 \mathrm{H})$.

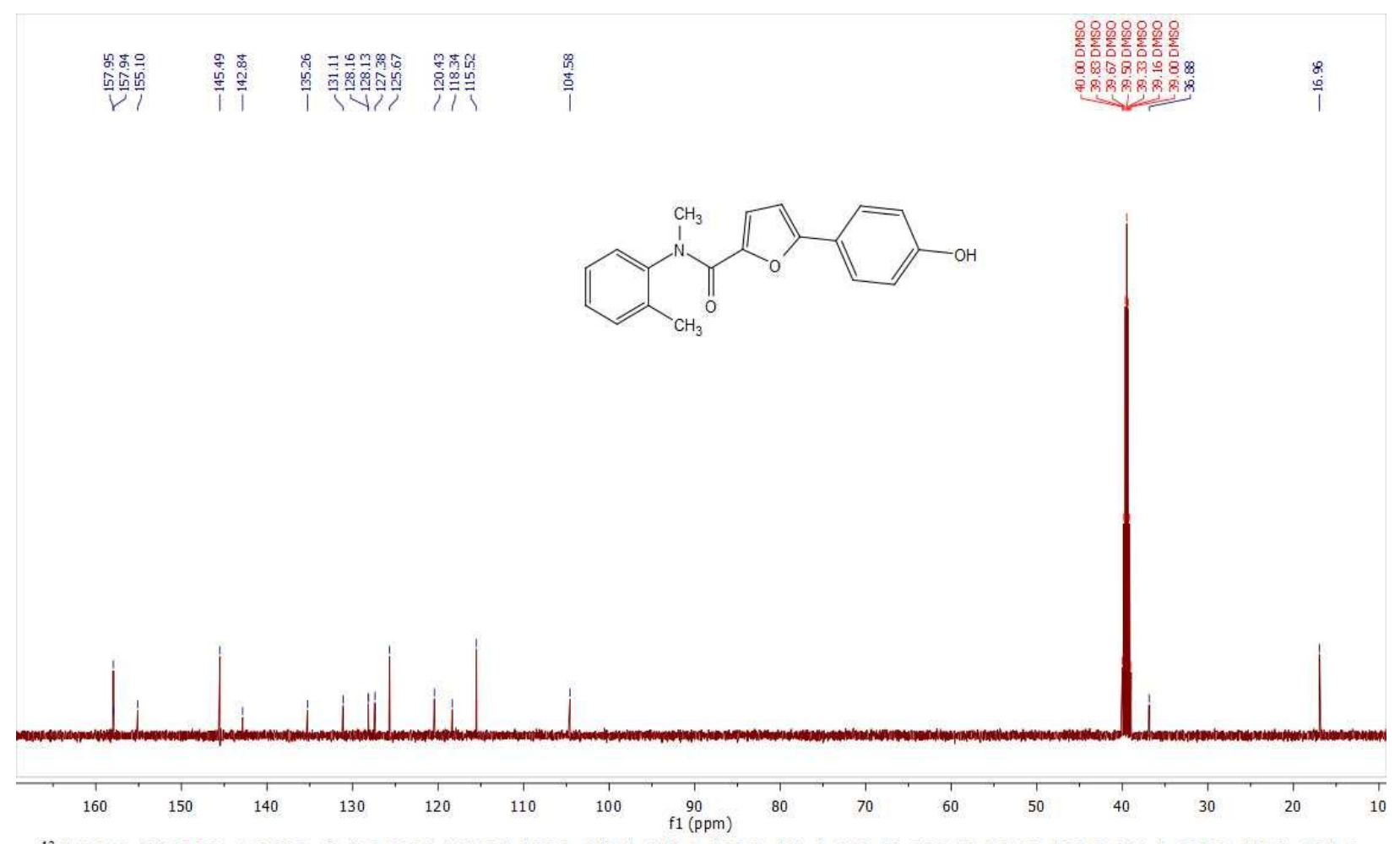

${ }^{13} \mathrm{C}$ NMR $\left(126 \mathrm{MHz}\right.$, DMSO-d $\left.{ }_{6}\right) \delta 157.95,157.94,155.1,145.4,142.8,135.2,131.1,128.16,128.13,127.3,125.6,120.4,118.3,115.5,104.5$, 36.8, 16.9 . 


\section{Compound 5:}

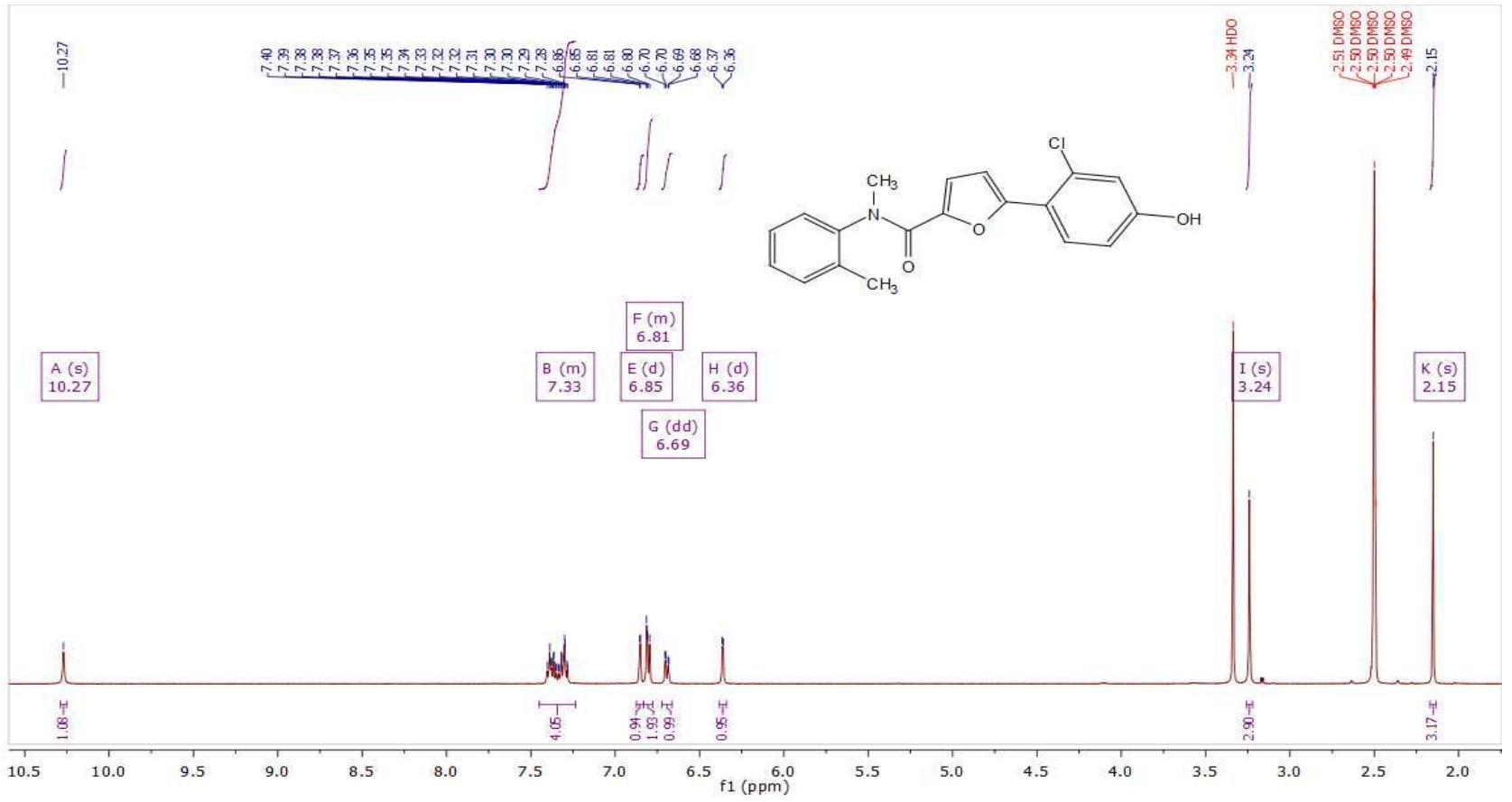

${ }^{1} \mathrm{H}$ NMR $\left(500 \mathrm{MHz}, \mathrm{DMSO}-d_{6}\right) \delta 10.27(\mathrm{~s}, 1 \mathrm{H}), 7.42-7.26(\mathrm{~m}, 4 \mathrm{H}), 6.85(\mathrm{~d}, J=2.4 \mathrm{~Hz}, 1 \mathrm{H}), 6.83-6.78(\mathrm{~m}, 2 \mathrm{H}), 6.69(\mathrm{dd}, J=8.7,2.5 \mathrm{~Hz}$, $1 \mathrm{H}), 6.36(\mathrm{~d}, J=3.7 \mathrm{~Hz}, 1 \mathrm{H}), 3.24(\mathrm{~s}, 3 \mathrm{H}), 2.15(\mathrm{~s}, 3 \mathrm{H})$.

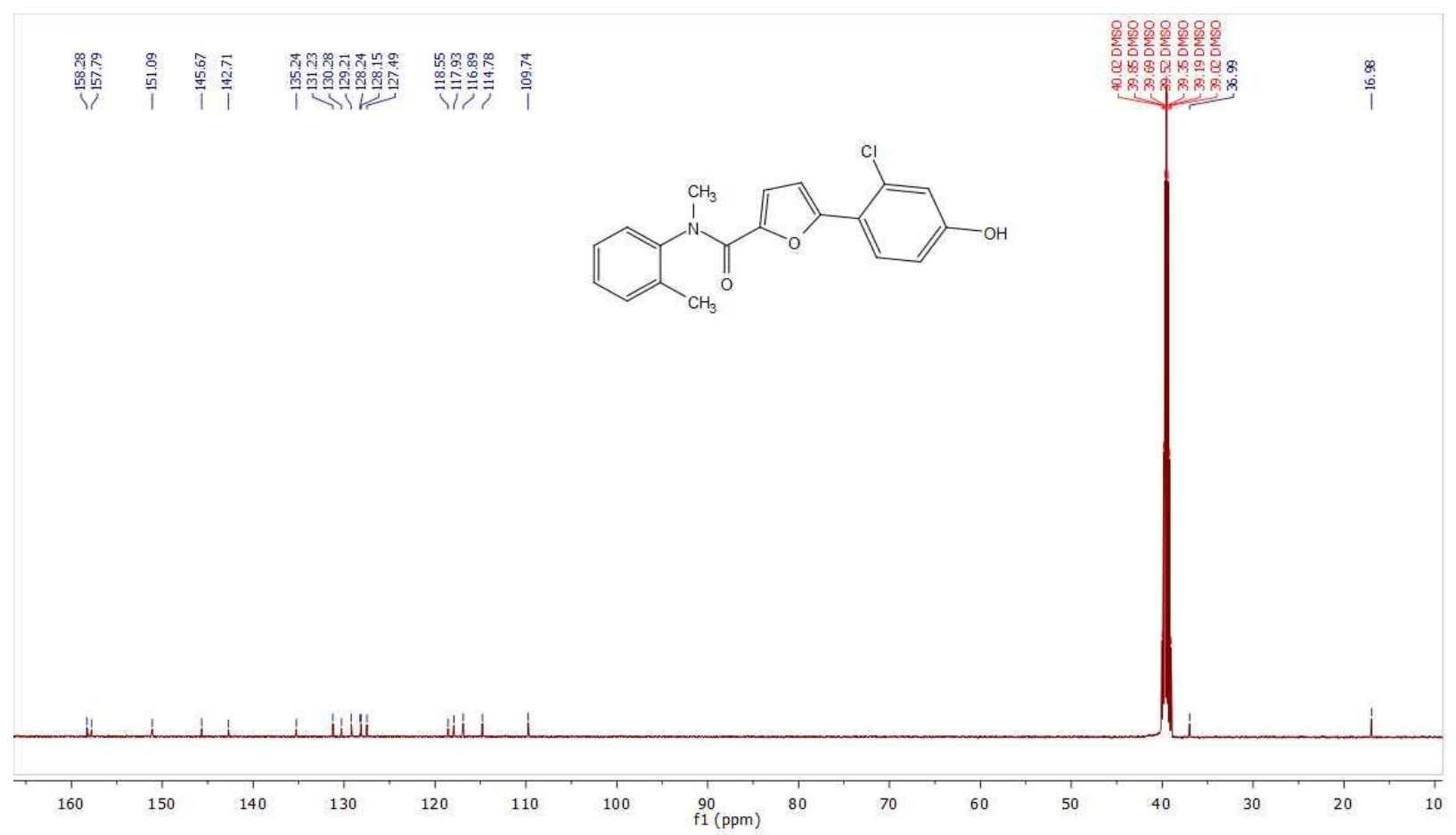

${ }^{13} \mathrm{C}$ NMR $\left(126 \mathrm{MHz}\right.$, DMSO- $\left.d_{6}\right) \delta 158.2,157.7,151.0,145.6,142.7,135.2,131.2,130.2,129.2,128.2,128.1,127.4,118.5,117.9,116.8,114.7$, 109.7, 36.9, 16.9. 


\section{Compound 6:}

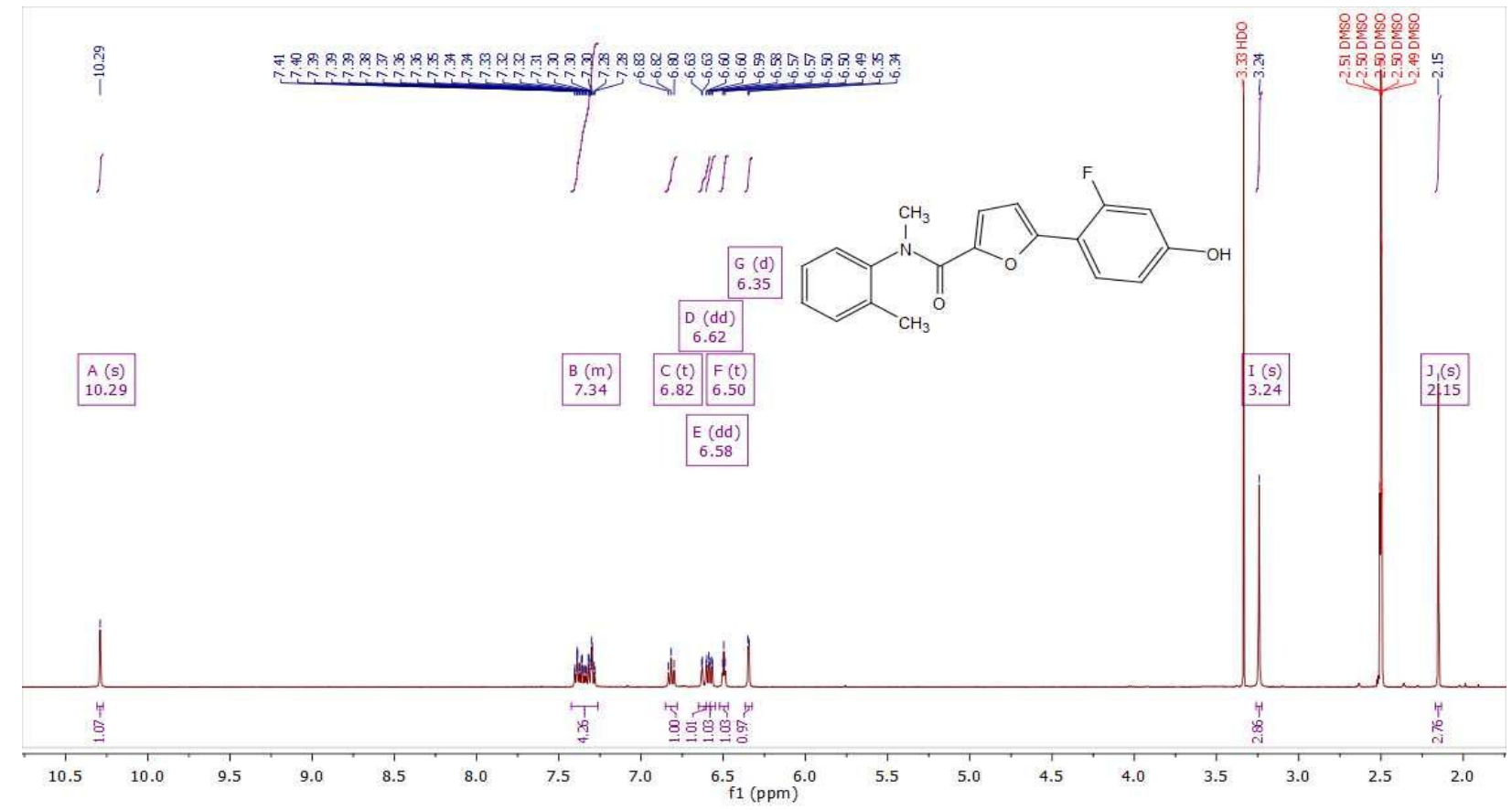

${ }^{1} \mathrm{H}$ NMR $\left(500 \mathrm{MHz}, \mathrm{DMSO}-d_{6}\right) \delta 10.29(\mathrm{~s}, 1 \mathrm{H}), 7.42-7.26(\mathrm{~m}, 4 \mathrm{H}), 6.82(\mathrm{t}, J=8.8 \mathrm{~Hz}, 1 \mathrm{H}), 6.62(\mathrm{dd}, J=13.1,2.3 \mathrm{~Hz}, 1 \mathrm{H}), 6.58(\mathrm{dd}, J=$ $8.6,2.4 \mathrm{~Hz}, 1 \mathrm{H}), 6.50(\mathrm{t}, J=3.6 \mathrm{~Hz}, 1 \mathrm{H}), 6.35(\mathrm{~d}, J=3.6 \mathrm{~Hz}, 1 \mathrm{H}), 3.24(\mathrm{~s}, 3 \mathrm{H}), 2.15(\mathrm{~s}, 3 \mathrm{H})$.

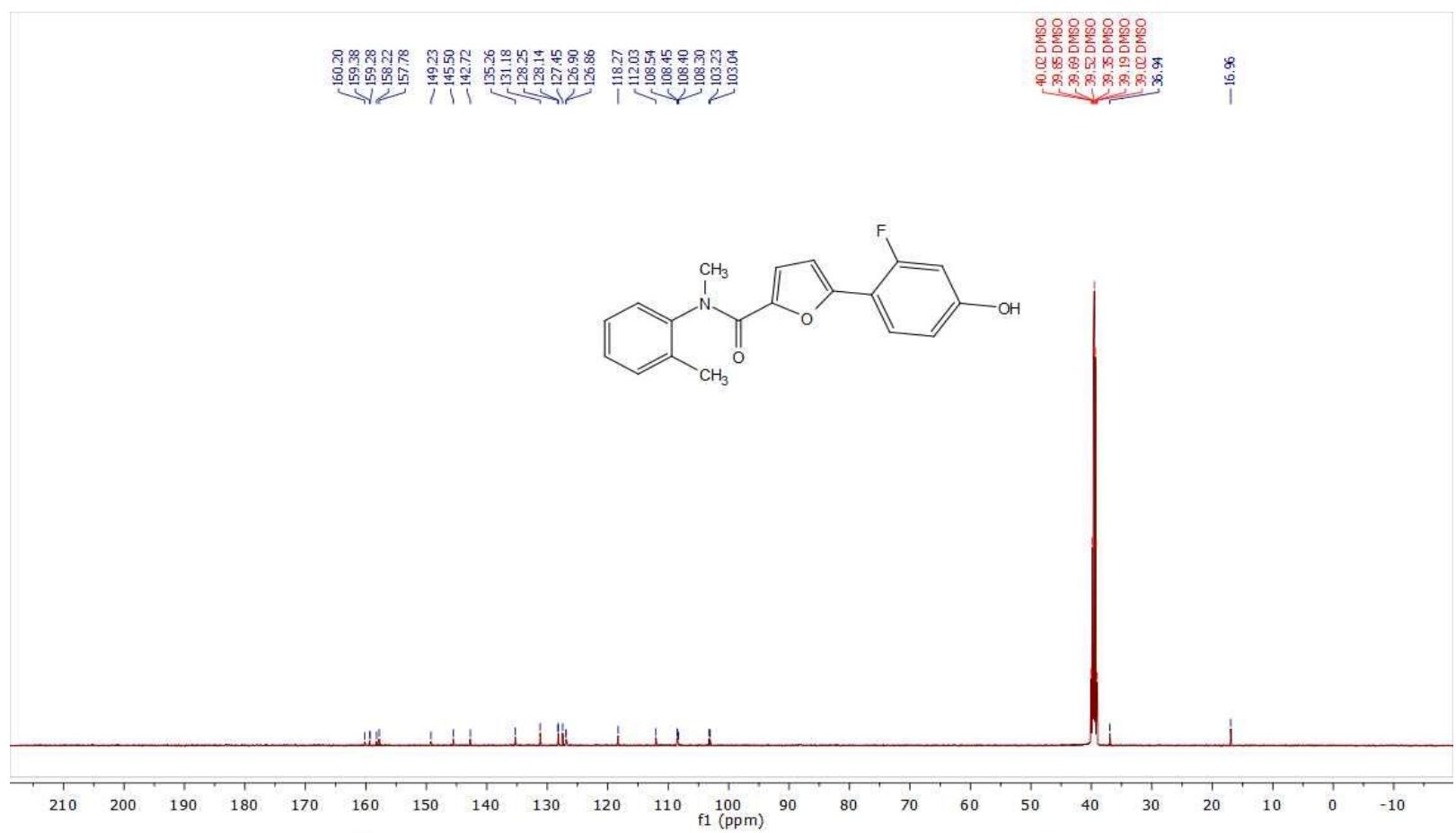

${ }^{13} \mathrm{C}$ NMR $(126 \mathrm{MHz}$, DMSO-d $)$ o $160.2,159.3,159.2,158.2,157.7,149.2,145.5,142.7,135.2,131.1,128.2,128.1,127.4,126.9,126.8$, $118.2,112.0,108.5,108.45,108.40,108.3,103.2,103.0,36.9,16.9$. 


\section{Compound 8:}

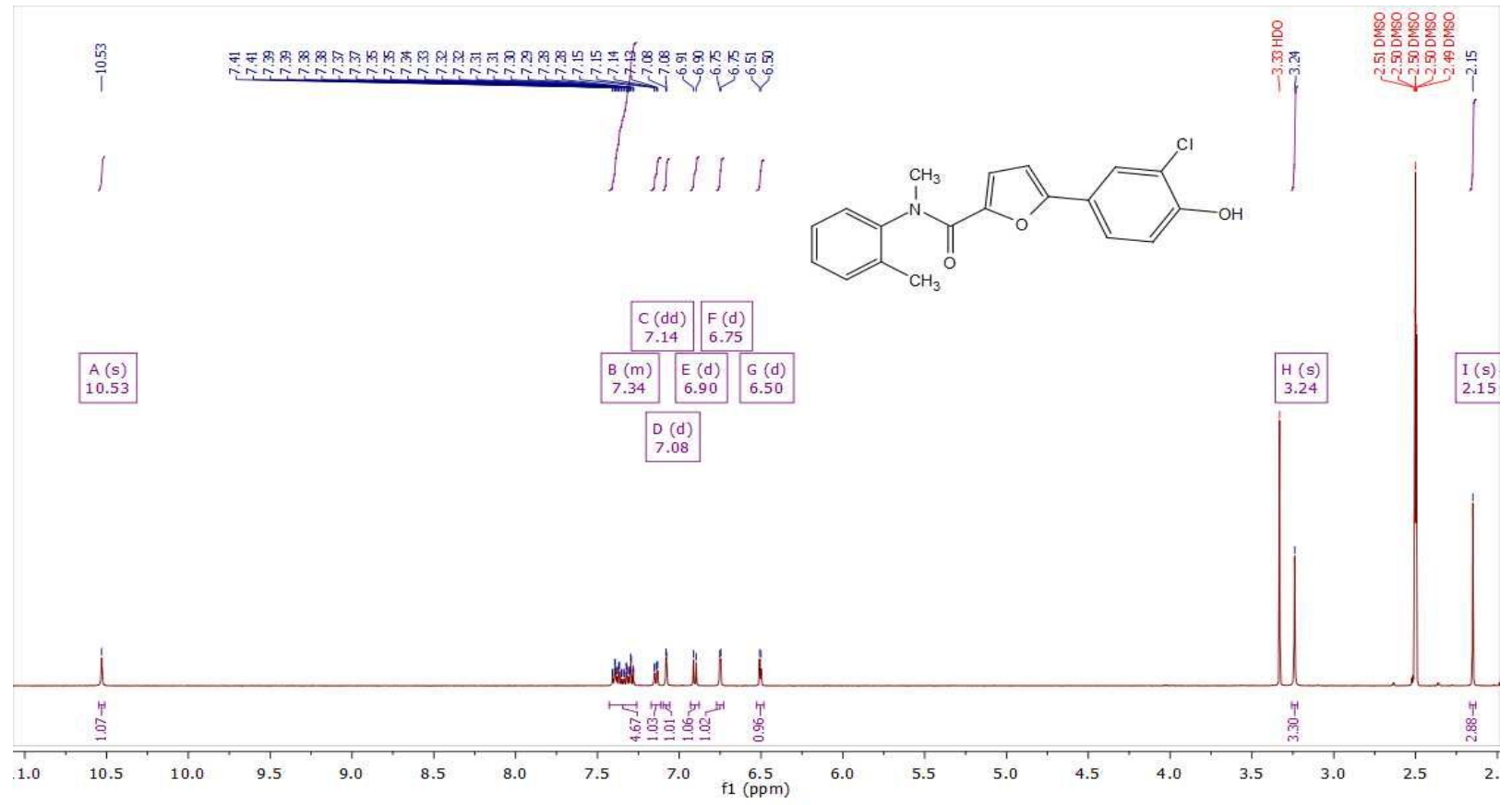

${ }^{1} \mathrm{H}$ NMR $\left(500 \mathrm{MHz}, \mathrm{DMSO}-d_{6}\right) \delta 10.53(\mathrm{~s}, 1 \mathrm{H}), 7.43-7.26(\mathrm{~m}, 5 \mathrm{H}), 7.14(\mathrm{dd}, J=8.5,2.2 \mathrm{~Hz}, 1 \mathrm{H}), 7.08(\mathrm{~d}, J=2.2 \mathrm{~Hz}, 1 \mathrm{H}), 6.90(\mathrm{~d}, J=$ $8.5 \mathrm{~Hz}, 1 \mathrm{H}), 6.75(\mathrm{~d}, J=3.6 \mathrm{~Hz}, 1 \mathrm{H}), 6.50(\mathrm{~d}, J=3.6 \mathrm{~Hz}, 1 \mathrm{H}), 3.24(\mathrm{~s}, 3 \mathrm{H}), 2.15(\mathrm{~s}, 3 \mathrm{H})$.

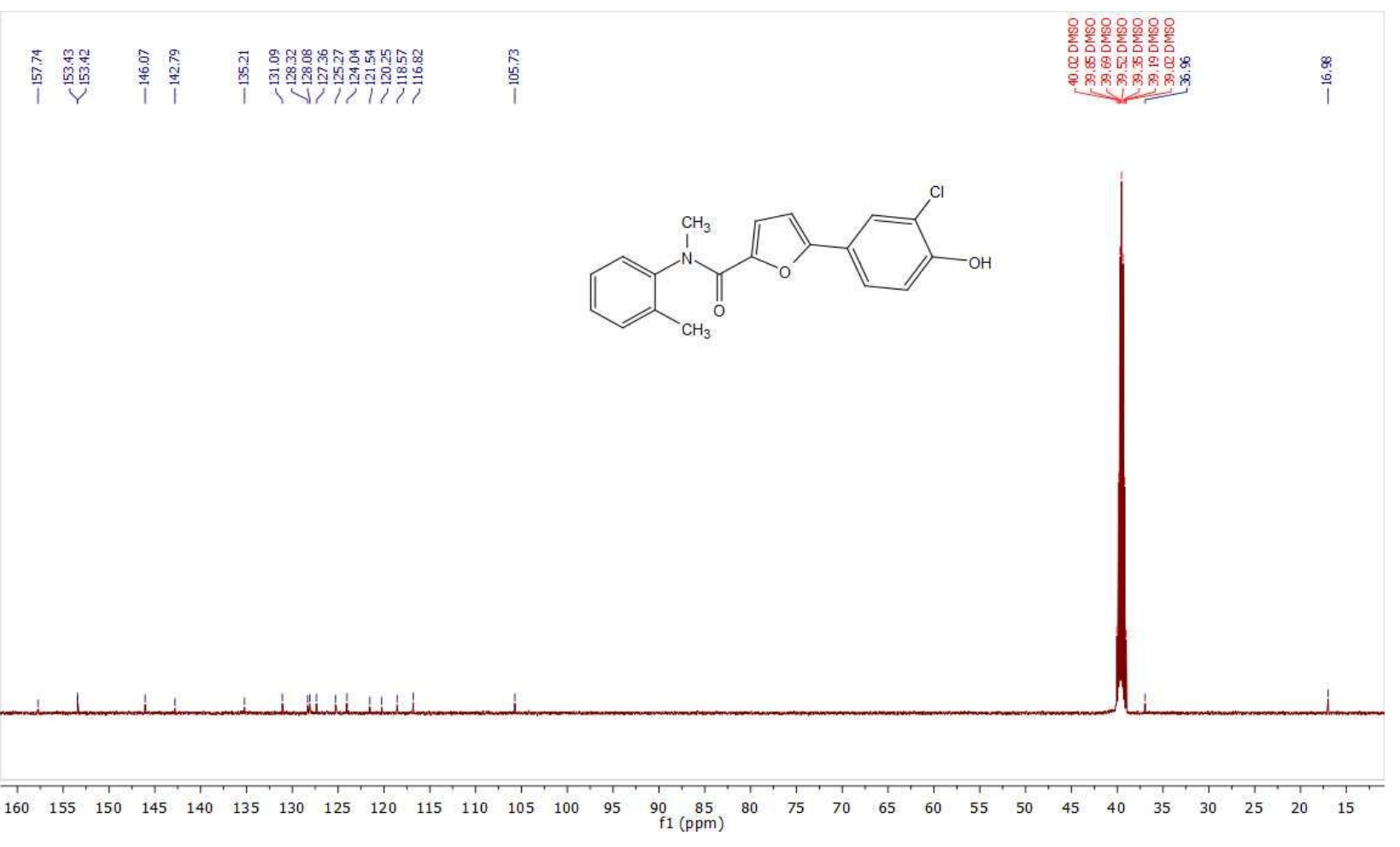

${ }^{13} \mathrm{C}$ NMR (126 MHz, DMSO-d 6 ) $\delta$ 157.7, 153.43, 153.42, 146.0, 142.7, 135.2, 131.0, 128.3, 128.0, 127.3, 125.2, 124.0, 121.5, 120.2, 118.5, 116.8, 105.7, 36.9, 16.9. 


\section{e) Representative chromatograms and MS spectra}

\section{Compound 1:}<smiles>Cc1ccccc1N(C)C(=O)c1ccc(-c2cc(C)c(O)c(C)c2)o1</smiles>

Molecular Weight: 335.40
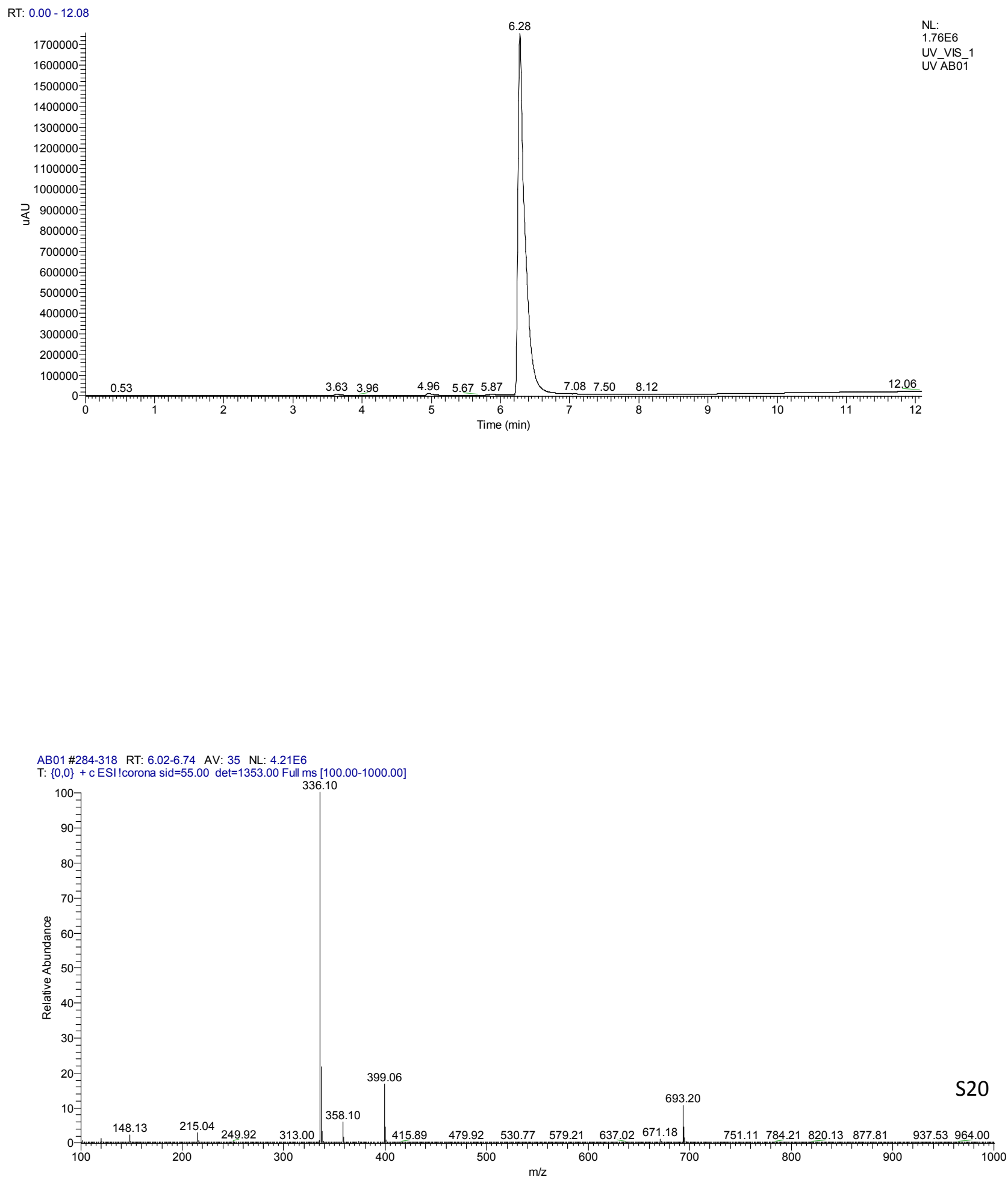


\section{Compound 2:}<smiles>Cc1cc(-c2ccc(C(=O)N(C)c3ccccc3C)o2)ccc1O</smiles>

Molecular Weight: 321.38
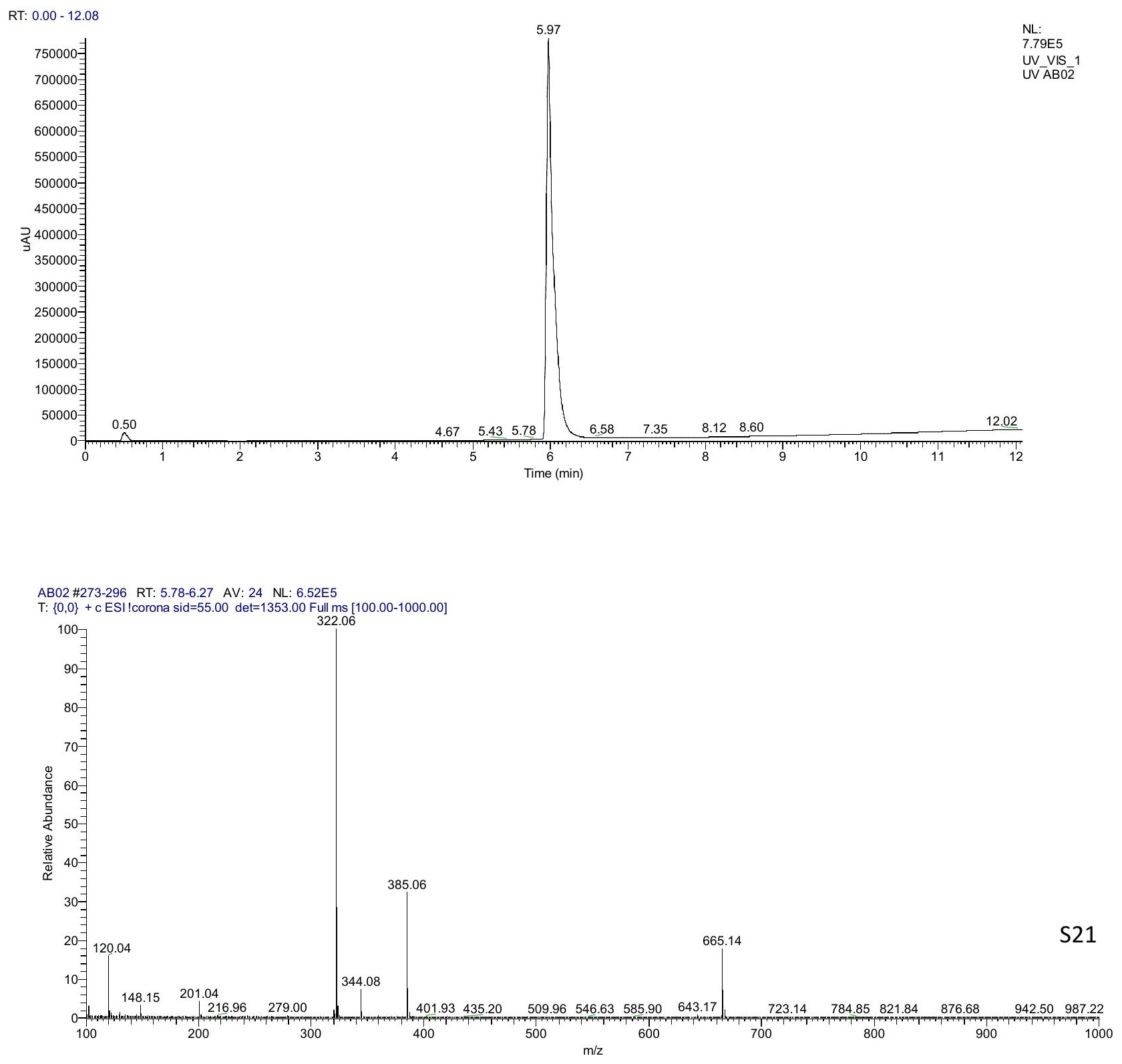


\section{Compound 4:}

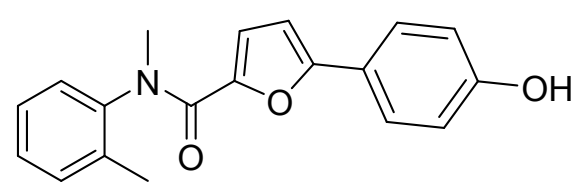

Molecular Weight: 307.35

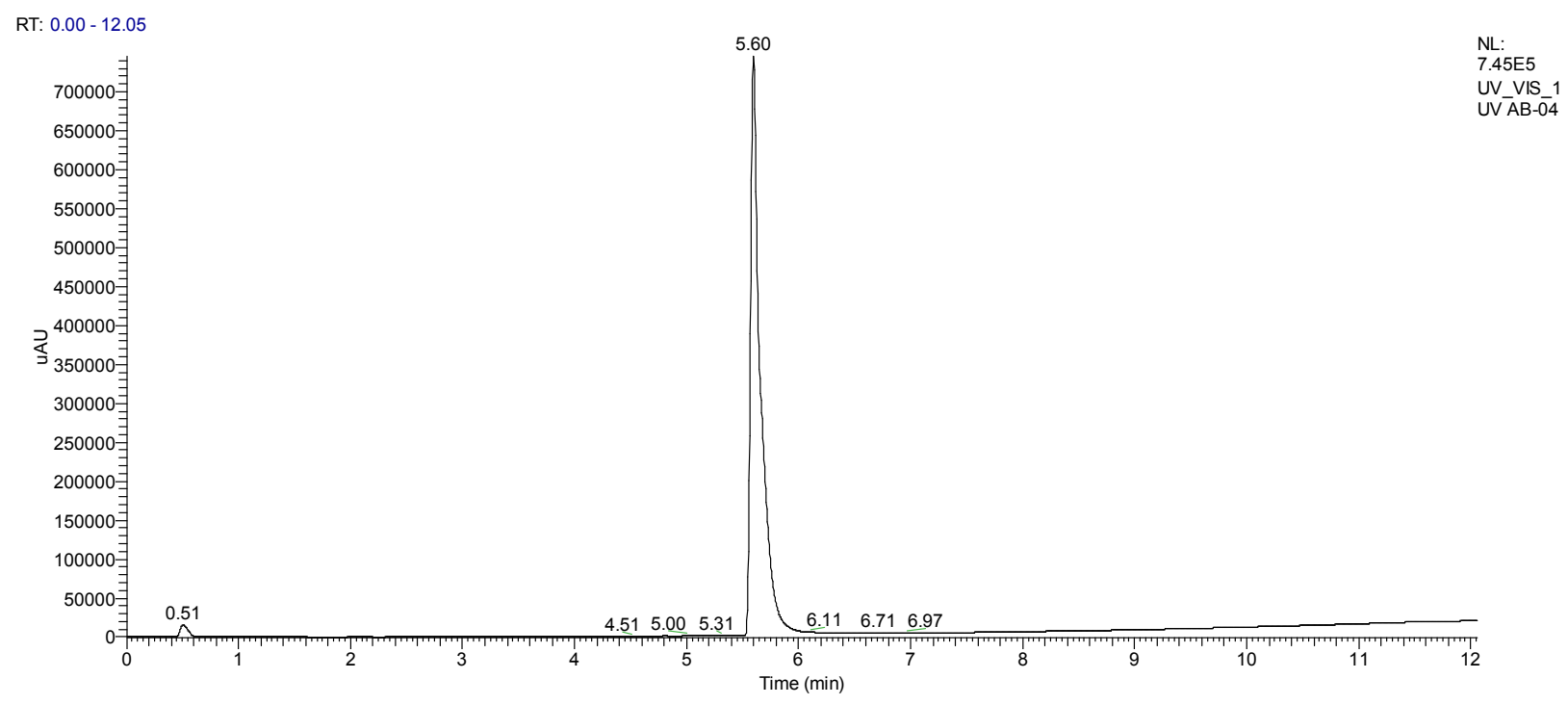




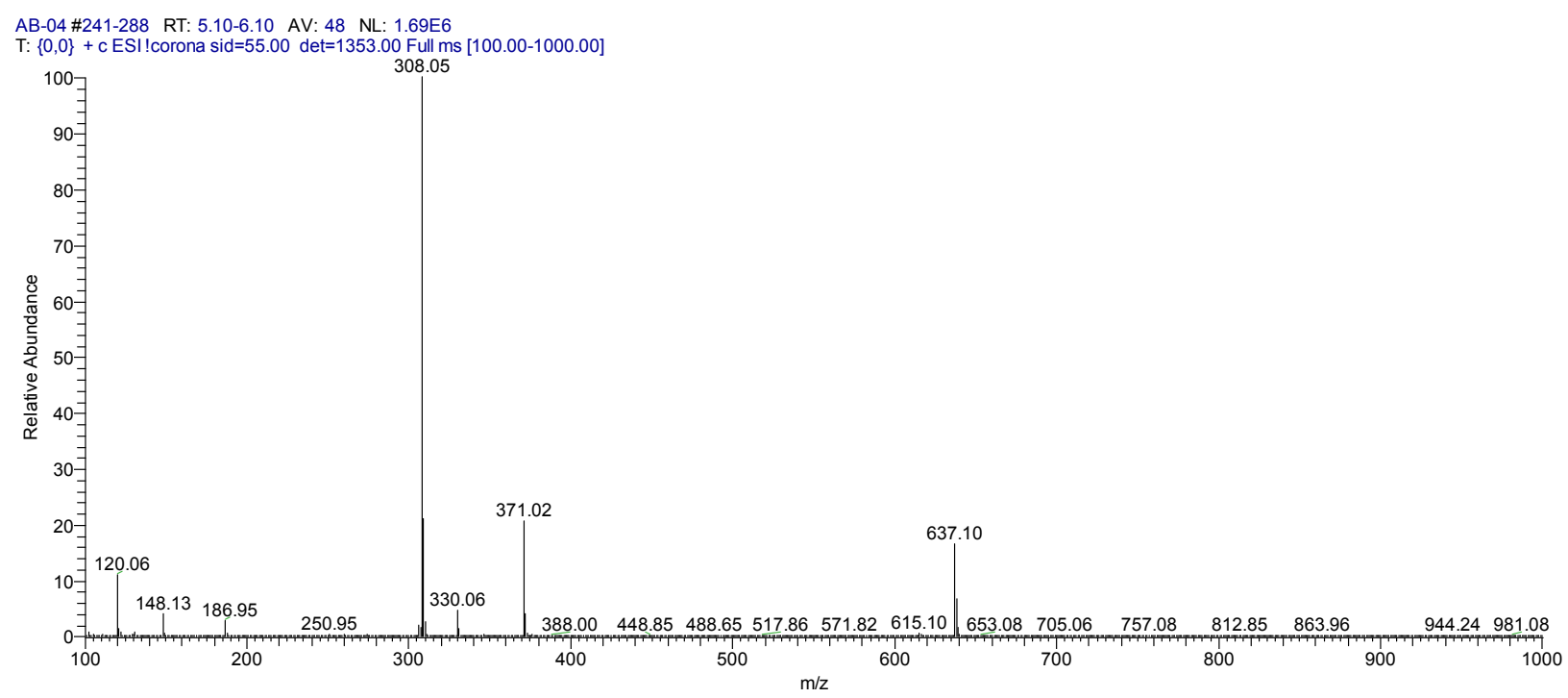

\section{Compound 5:}<smiles>Cc1ccccc1N(C)C(=O)c1ccc(-c2ccc(O)cc2Cl)o1</smiles>

Molecular Weight: 341.79

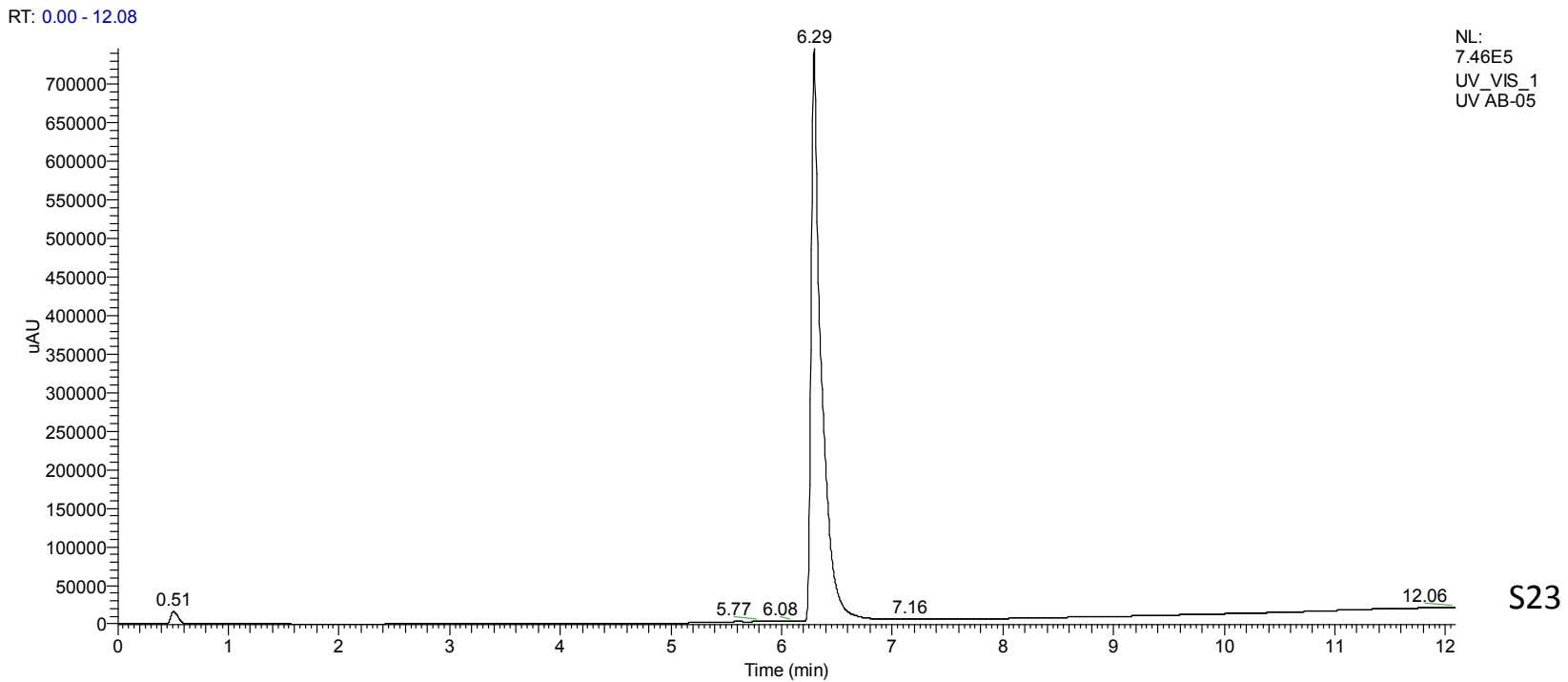




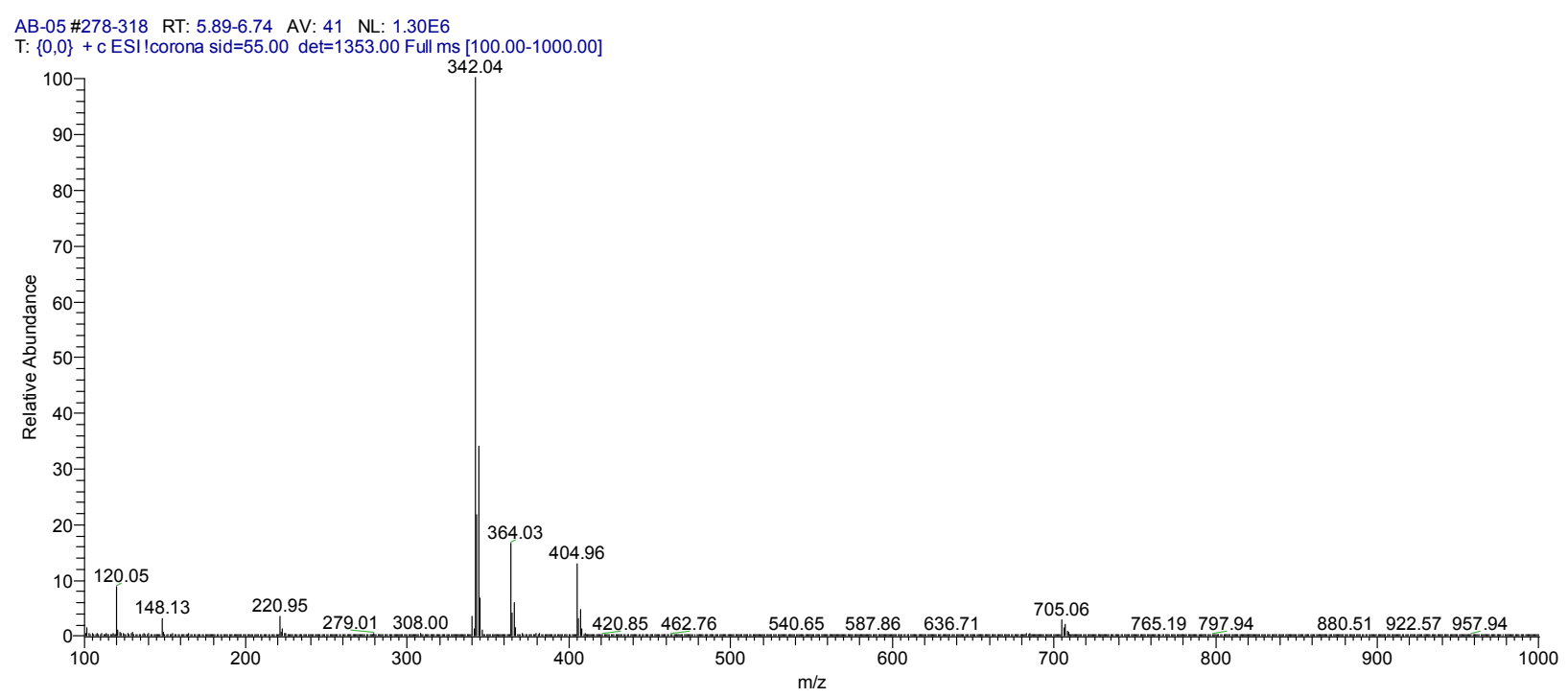

\section{Compound 7:}<smiles>Cc1ccccc1N(C)C(=O)c1ccc(-c2ccc(O)c(F)c2)o1</smiles>

Molecular Weight: 325.34 

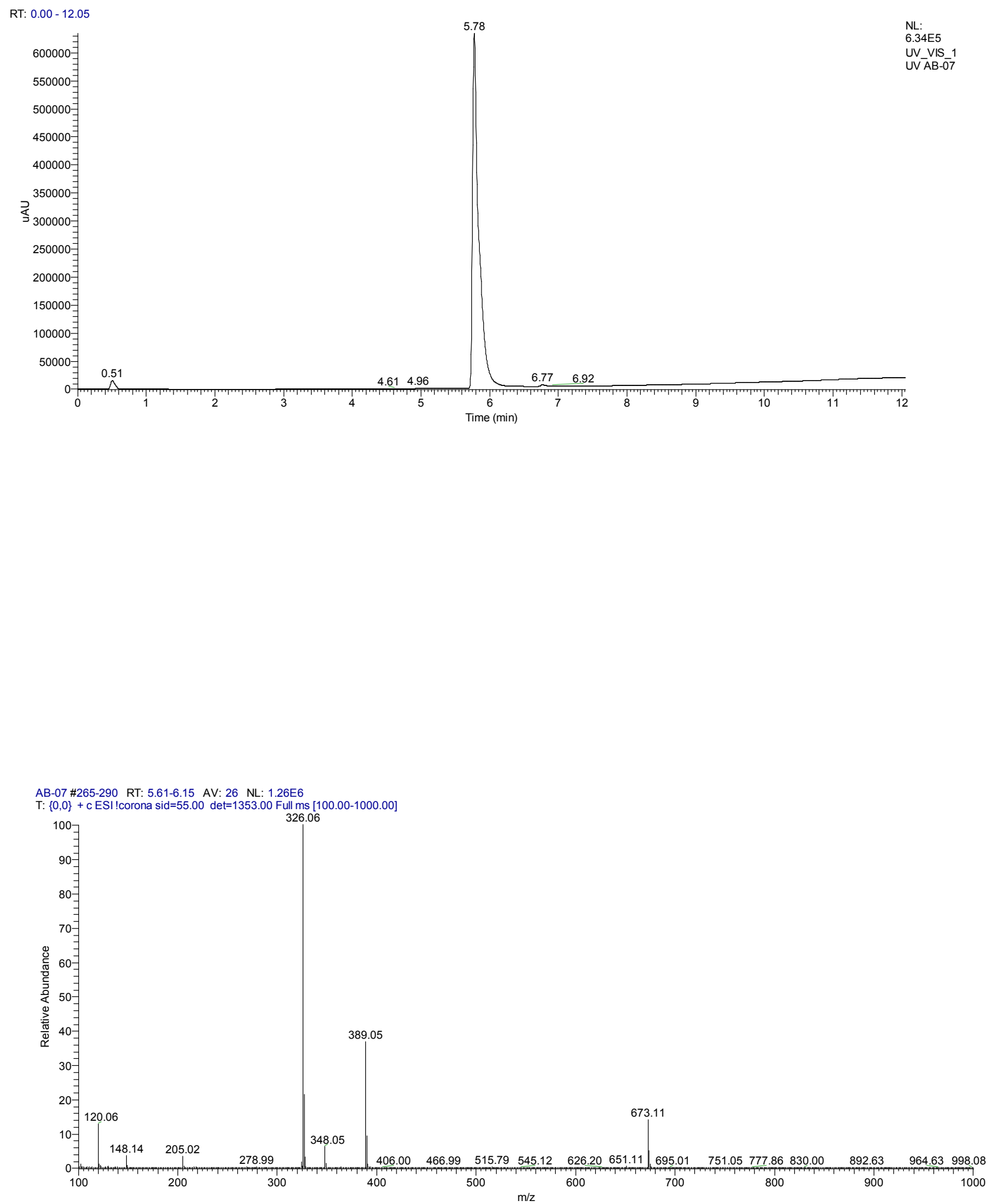


\section{Compound 8:}<smiles>Cc1ccccc1N(C)C(=O)c1ccc(-c2ccc(O)c(Cl)c2)o1</smiles>

Molecular Weight: 341.79
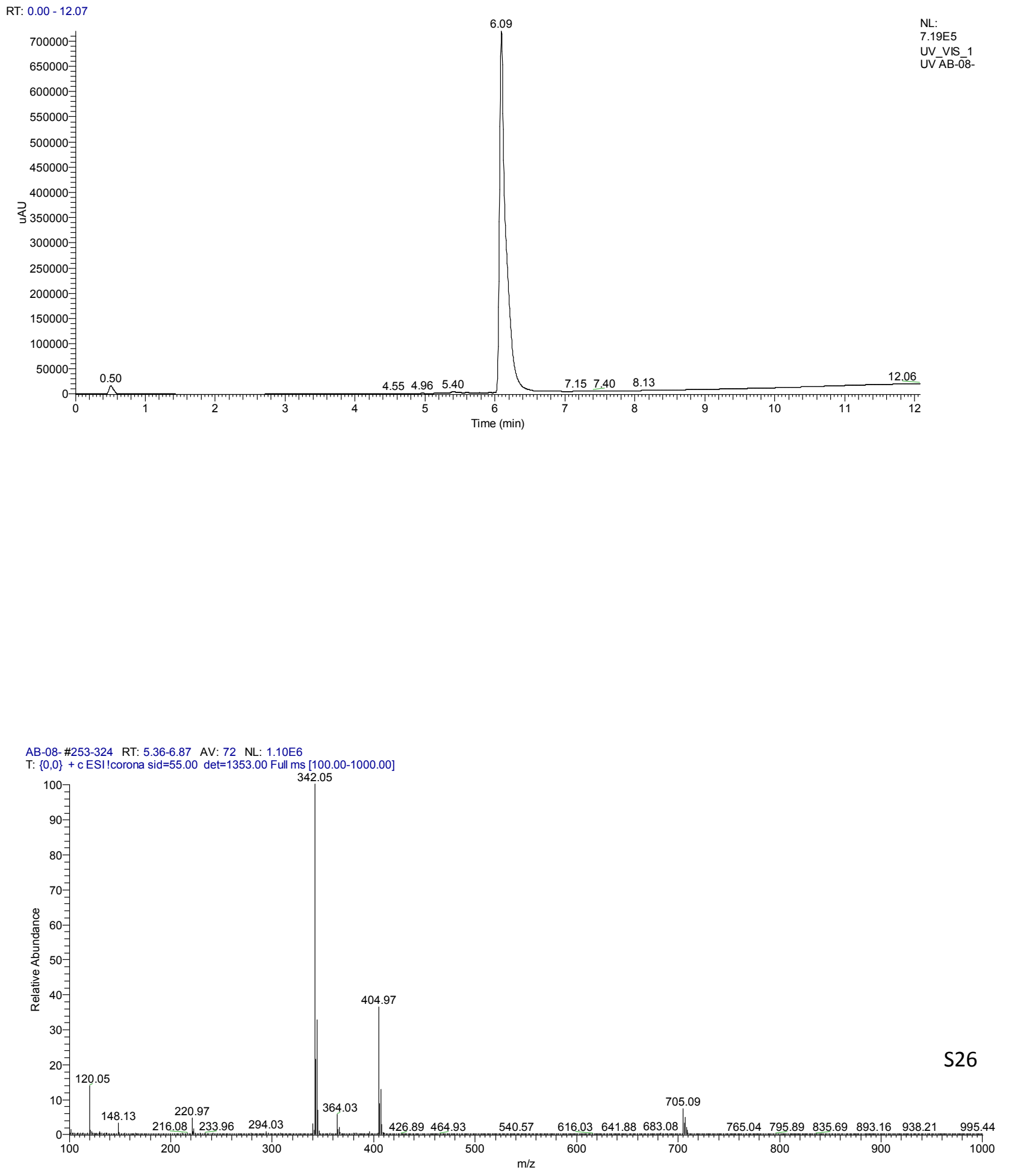
f)

on

formulas

data

Table S1:

on

formulas,

masses

masses for

\begin{tabular}{|c|c|c|c|c|}
\hline Compound & $\begin{array}{l}\text { Molecular } \\
\text { Formula } \\
\end{array}$ & $\begin{array}{l}\text { Mass required } \\
\text { (Exact Mass) }\end{array}$ & $\begin{array}{l}\text { Mass found } \\
{[\mathrm{M}+\mathrm{H}]^{+}}\end{array}$ & \multirow{5}{*}{$\begin{array}{l}\text { Overview } \\
\text { molecular } \\
\text { and MS }\end{array}$} \\
\hline $1 \mathrm{~b}$ & $\mathrm{C}_{13} \mathrm{H}_{12} \mathrm{BrNO}_{2}$ & 293.01 & $293.98,295.97^{*}$ & \\
\hline $1 \mathbf{a}$ & $\mathrm{C}_{22} \mathrm{H}_{23} \mathrm{NO}_{3}$ & 349.17 & 350.18 & \\
\hline $2 \mathbf{a}$ & $\mathrm{C}_{21} \mathrm{H}_{21} \mathrm{NO}_{3}$ & 335.15 & 336.15 & \\
\hline $3 \mathbf{a}$ & $\mathrm{C}_{21} \mathrm{H}_{21} \mathrm{NO}_{3}$ & 335.15 & 336.27 & \\
\hline $4 a$ & $\mathrm{C}_{20} \mathrm{H}_{19} \mathrm{NO}_{3}$ & 321.14 & 322.12 & \multirow{3}{*}{$\begin{array}{l}\text { Overview } \\
\text { molecular } \\
\text { required } \\
\text { and found }\end{array}$} \\
\hline $5 \mathbf{a}$ & $\mathrm{C}_{20} \mathrm{H}_{18} \mathrm{ClNO}_{3}$ & 355.10 & $356.06,358.07^{*}$ & \\
\hline $6 \mathbf{a}$ & $\mathrm{C}_{20} \mathrm{H}_{18} \mathrm{FNO}_{3}$ & 339.13 & 340.13 & \\
\hline
\end{tabular}

\begin{tabular}{|l|l|l|l|}
\hline $\mathbf{7}$ & $\mathrm{C}_{20} \mathrm{H}_{18} \mathrm{FNO}_{3}$ & 339.13 & 340.22 \\
\hline $\mathbf{9 a}$ & $\mathrm{C}_{20} \mathrm{H}_{17} \mathrm{~F}_{2} \mathrm{NO}_{3}$ & 357.12 & 357.90 \\
\hline $\mathbf{1 0 a}$ & $\mathrm{C}_{20} \mathrm{H}_{17} \mathrm{Cl}_{2} \mathrm{NO}_{3}$ & 389.06 & $390.15,392.09^{*}$ \\
\hline $\mathbf{1}$ & $\mathrm{C}_{21} \mathrm{H}_{21} \mathrm{NO}_{3}$ & 335.15 & 336.10 \\
\hline $\mathbf{2}$ & $\mathrm{C}_{20} \mathrm{H}_{19} \mathrm{NO}_{3}$ & 321.14 & 322.06 \\
\hline $\mathbf{3}$ & $\mathrm{C}_{20} \mathrm{H}_{19} \mathrm{NO}_{3}$ & 321.14 & 322.20 \\
\hline $\mathbf{4}$ & $\mathrm{C}_{19} \mathrm{H}_{17} \mathrm{NO}_{3}$ & 307.12 & 308.05 \\
\hline $\mathbf{5}$ & $\mathrm{C}_{19} \mathrm{H}_{16} \mathrm{ClNO}_{3}$ & 341.08 & $342.04,344.09 *$ \\
\hline $\mathbf{6}$ & $\mathrm{C}_{19} \mathrm{H}_{16} \mathrm{FNO}_{3}$ & 325.11 & 326.01 \\
\hline $\mathbf{7}$ & $\mathrm{C}_{19} \mathrm{H}_{16} \mathrm{FNO}_{3}$ & 325.11 & 326.06 \\
\hline $\mathbf{8}$ & $\mathrm{C}_{19} \mathrm{H}_{16} \mathrm{ClNO}_{3}$ & 341.08 & $342.05,344.01 *$ \\
\hline $\mathbf{9}$ & $\mathrm{C}_{19} \mathrm{H}_{15} \mathrm{~F}_{2} \mathrm{NO}_{3}$ & 343.10 & 344.22 \\
\hline $\mathbf{1 0}$ & $\mathrm{C}_{19} \mathrm{H}_{15} \mathrm{Cl}_{2} \mathrm{NO}_{3}$ & 375.04 & $376.14,378.10^{*}$ \\
\hline
\end{tabular}

compounds $\mathbf{1 a}-\mathbf{1 0 a}, \mathbf{1 b}$ and $\mathbf{1}-\mathbf{1 0}$ 
*Higher value corresponds to molecular species containing the heavier halogen isotope $(\mathrm{Cl}, \mathrm{Br})$. 


\section{g) References}

(1) Marchais-Oberwinkler, S.; Wetzel, M.; Ziegler, E.; Kruchten, P.; Werth, R.; Henn, C.; Hartmann, R. W.; Frotscher, M. New Drug-Like HydroxyphenylnaphtolSteroidomimetics As Potent and Selective 17 $\beta$-Hydroxysteroid Dehydrogenase Type 1 Inhibitors for the Treatment of Estrogen-Dependent Diseases. J. Med. Chem.2011, 54, 534-547.

(2) Perspicace, E.; Giorgio, A.; Carotti, A.; Marchais-Oberwinkler, S.; Hartmann, R. W. Novel Nmethylsulfonamide and retro-N-methylsulfonamidederivatives as $17 \beta$-hydroxysteroiddehydrogenase type 2 (17ß-HSD2) inhibitorswith good ADME-relatedphysicochemicalparameters. Eur. J. Med. Chem. 2013, 69, 201-205.

(3) Zhu, D. W.; Lee, X.; Breton, R.; Ghosh, D.; Pangborn, W.;Duax, W. L.; Lin, S.-X. Crystallization and preliminary X-ray diffraction analysis of the complex of human placental 17 beta-hydroxysteroid dehydrogenase with NADP. J. Mol. Biol. 1993, 234, 242-244.

(4) Puranen, T. J.; Poutanen, M. H.; Peltoketo, H. E.; Vihko, P. T.; Vihko, R. K. Site-directed mutagenesis of the putative active site of human 17 beta-hydroxysteroid dehydrogenase type 1 . Biochem. J 1994, 304, 289-93.

(5) Jazbutyte, V.; Hu, K.; Kruchten, P.; Bey, E.; Maier, S. K.; Fritzemeier, K. H.; Prelle, K.; HegeleHartung, C.; Hartmann, R. W.; Neyses, L.; Ertl, G.; Pelzer, T. Aging reduces the efficacy of estrogen substitution to attenuate cardiac hypertrophy in female spontaneously hypertensive rats. Hypertension 2006, 48, 579-86.

(6) Xu, K.; Wetzel, M.; Hartmann, R. W.; Marchais-Oberwinkler, S. Synthesis and biological evaluation of spiro- $\delta$-lactones as inhibitors of $17 \beta$-hydroxysteroid dehydrogenase type 2 (17 $\beta$-HSD2). Lett. Drug Des. Discov. 2011, 8, 406-421.

(7) Lin, S. X.; Yang, F.; Jin, J. Z.; Breton, R.; Zhu, D. W.; Luu-The, V.; Labrie, F. Subunit identity of the dimeric 17 beta-hydroxysteroid dehydrogenase from human placenta. J. Biol. Chem. 1992, 274, 2876228770.

(8) EDSP, Protocol for the In Vitro Estrogen Receptor Saturation Binding and Competitive Binding Assays Using Rat Uterine Cytosol. Available via http://www.epa.gov/endo/pubs/assayvalidation/appendix1_er ruc.pdf. 2009.

(9) Di, L.; Kerns, E. H.; Hong, Y.; Kleintop, T. A.; McConnell, O. J.; Huryn, D. M. Optimization of a Higher Throughput Microsomal Stability Screening Assay for Profiling Drug Discovery Candidates. J. Biomol. Screen. 2003, 8, 453-462.

(10) Moreno-Farre, J.; Workman, P.; Raynud, F. Analysis of Potential Drug-Drug Interactions for Anticancer Agents in Human Liver Microsomes by High Throughput Liquid Chromatography/Mass Spectrometry Assay. Aust.-Asian J. Cancer 2007, 6, 55-69.

(11) Hui, J. P. M.; Grossert, J. S.; Cutler, M. J.; Melanson, J. E. Strategic identification of in vitro metabolites of 13-desmethyl spirolide $\mathrm{C}$ using liquid chromatography/high-resolution mass spectrometry. Rapid. Commun. Mass. Sp. 2011, 26, 345-354.

(12) Denizot, F.; Lang, R. Rapid colorimetric assay for cell growth and survival. Modifications to the tetrazolium dye procedure giving improved sensitivity and reliability. J. Immunol.Methods 1986, 89, 271-7.

(13) Cornell, W. D.; Cieplak, P.; Bayly, C. I.; Kollmann, P. A. Application of RESP charges to calculate conformational energies, hydrogen bond energies, and free energies of solvation. J. Am. Chem. Soc. 1993, 115, 9620-9631.

(14) Becke, A. D. Density-functional thermochemistry. III. The role of exact exchange. J. Chem. Phys. 1993, 98, 5648-5652.

(15) Frisch, M. J.; Trucks, G. W.; Schlegel, H. B.; Scuseria, G. E.; Robb, M. A.; Cheeseman, J. R.; Scalmani, G.; Barone, V.; Mennucci, B.; Petersson, G. A.; Nakatsuji, H.; Caricato, M.; Li, X.; Hratchian, H. P.; Izmaylov, A. F.; Bloino, J.; Zheng, G.; Sonnenberg, J. L.; Hada, M.; Ehara, M.; Toyota, K.; Fukuda, R.; Hasegawa, J.; Ishida, M.; Nakajima, T.; Honda, Y.; Kitao, O.; Nakai, H.; Vreven, T.; Montgomery, 
J. A., Jr.; Peralta, J. E.; Ogliaro, F.; Bearpark, M.; Heyd, J. J.; Brothers, E.; Kudin, K. N.; Staroverov, V. N.; Kobayashi, R.; Normand, J.; Raghavachari, K.; Rendell, A.; Burant, J. C.; Iyengar, S. S.; Tomasi, J.; Cossi, M.; Rega, N.; Millam, J. M.; Klene, M.; Knox, J. E.; Cross, J. B.; Bakken, V.; Adamo, C.; Jaramillo, J.; Gomperts, R.; Stratmann, R. E.; Yazyev, O.; Austin, A. J.; Cammi, R.; Pomelli, C.; Ochterski, J. W.; Martin, R. L.; Morokuma, K.; Zakrzewski, V. G.; Voth, G. A.; Salvador, P.; Dannenberg, J. J.; Dapprich, S.; Daniels, A. D.; Farkas, Ö.; Foresman, J. B.; Ortiz, J. V.; Cioslowski, J.; Fox, D. J. Gaussian 09, revision A.2, Gaussian, Inc.: Wallingford, CT, 2009.

(16) Mazumdar, M.; Fournier, D.; Zhu, D. W.; Cadot, C.; Poirier, D.; Lin, S. X. Binary and ternary crystal structure analyses of a novel inhibitor with 17beta-HSD type 1: a lead compound for breast cancer therapy. Biochem. J. 2009, 424, 357-366.

(17) Schrödinger Suite 2015-3: Scrödinger, LLC, New York, NY, 2015.

(18) Small-Molecule Drug Discovery Suite 2015-3: Glide, version 6.8, Scheödinger, LLC, New York, NY, 2015.

(19) Sherbet, D. P.; Papari-Zareei, M.; Khan, N.; Sharma, K. K.; Brandmaier, A.; Rambally, S.; Chattopadhyay, A.; Andersson, S.; Agarwal, A. K.; Auchus, R. J. Cofactors, redox state, and directional preferences of hydroxysteroid dehydrogenases. Mol. Cell. Endocrinol. 2007, 265-266, 83-8. 